\title{
Chilly Climates, Balancing Acts, and Shifting Pathways: What Happens to Women in STEM Doctoral Programs
}

\author{
Marilyn Cabay ${ }^{1}$, Bianca L. Bernstein ${ }^{2, *}$, Melissa Rivers ${ }^{3}$ and Natalie Fabert ${ }^{4}$ \\ 1 Supportive Psychological Services, Scottsdale, 4300 N Miller Rd., 110-5, Scottsdale, AZ 85251, USA; \\ marilyn.cabay@asu.edu \\ 2 Counseling and Counseling Psychology, Arizona State University, PO Box 870811, Tempe, AZ 85287, USA \\ 3 Educational Leadership, Northern Arizona University, PO Box 5774, Flagstaff, AZ 86011, USA; \\ mbrivers12@gmail.com \\ 4 Counseling Services, Arizona State University, PO Box 872104, Tempe, AZ 85287, USA; nfabert@asu.edu \\ * Correspondence: bbernstein@asu.edu
}

Received: 16 December 2017; Accepted: 21 January 2018; Published: 31 January 2018

\begin{abstract}
Women in doctoral programs in Science, Technology, Engineering and Math (STEM) leave without finishing at higher rates than men and, as with men, turn away from academic and research careers. This qualitative study examines the day-to-day influences on female doctoral students during their third or fourth year in physical science and engineering programs. Ethnographic cognitive interviewing and online incident reports document the specific experiences and reactions of 28 participants over a six-month period. The data were analyzed to identify key incidents, categories and recurring themes. Some incidents contributed to women's growing sense of competence, recognition and identification of oneself as a scientist. Others fit a model of microaggressions and gender barriers in a predominantly masculine culture. Problems of work-life balance were demonstrated for some women. Incidents generated responses by some participants that they would disengage from a research-intensive career trajectory toward alternate career interests outside of academic research. The findings provide information about the lived experiences of women in doctoral programs and suggest that the metaphor of career pathways may be more useful than pipelines in explaining the direction of women who are advanced doctoral students in research-intensive fields.
\end{abstract}

Keywords: women; graduate students; science and engineering; STEM; gender inequity

Gaps between men and women persist in the pursuit and outcomes of degrees in science, technology, engineering, and math (STEM) (Shauman 2017; Turk-Bicakci and Berger 2014). In the life and social sciences, women have closed the gap in undergraduate majors and admission to graduate programs and now exceed men in completion of doctoral programs (National Science Foundation 2017). Yet women are awarded fewer than $25 \%$ of the doctoral degrees in the physical sciences and engineering, and hold disproportionately fewer tenured faculty positions in STEM and far fewer positions of prestige and power (Bernstein 2011; Handelsman et al. 2005; Fox 2001; National Science Foundation 2017).

The "leaky pipeline" metaphor commonly refers to the disproportionate exit of women from STEM at transitions from one educational or career level to another, the consequence of which is fewer and fewer women remaining in the "pool" for subsequent advancement in STEM (Goulden et al. 2009). The pipeline metaphor relies on a somewhat linear conception of careers with certain specified outcomes, such as moving from an undergraduate major in STEM, through PhD degrees and postdocs, to faculty positions, to tenure, and eventually to full rank in research universities. Previous research on why women leave STEM fields at a greater rate than their male counterparts has examined the motivation of women to pursue STEM undergraduate degrees (Beyer 2014; Griffith 2010; Grunert and Bobnerb 2011; London et al. 
2011; Nadelson et al. 2015; Wyer 2003; Du 2006). Other research has focused on the challenges women face in academic and STEM careers that contribute to leaving (Fouad et al. 2016; Glass et al. 2013; Mason and Ekman 2007; Mason et al. 2013; Moss-Racusin et al. 2012).

The doctoral program in STEM fields is a unique phase in the progression and direction of STEM careers. Earning a doctoral degree represents a crucial milestone toward a professional career in STEM (Shauman 2017). Attrition from PhD programs, i.e., leaks in the pipeline before earning the degree, is particularly costly to individuals and to society. Evidence that cumulative ten-year Ph.D. completion rates are as low as 57\% in math, physical science and engineering fields (King 2008) is alarming and has motivated researchers to make doctoral attrition a focus of study (Golde 2005; Lott et al. 2009; Lovitts 2001; Nettles and Millett 2006; Sowell et al. 2015).

Women who enter research doctorate programs in science and engineering have already demonstrated their scientific credentials to compete for admission successfully. Their decision to enter a doctoral program represents a strong commitment to the chosen field and readiness to engage in a demanding and expensive journey toward a STEM career that requires a PhD. Yet, the data show that for women, more than for men, the leak continues during doctoral programs. Specifically, there is a substantial gender gap, with the cumulative proportion of women completing PhDs, within 10 years from entry, trailing men by nine percentage points in engineering and seven percentage points in math and physical sciences (King 2008). Hence, understanding women's graduate school experiences has taken on particular significance (Bernstein and Russo 2008; De Welde and Laursen 2011; Fabert and Bernstein 2009; Ferreira 2003a, 2003b; Herzig 2004a, 2004b).

Acknowledged, but not yet understood, is graduate students' movement away from their initial goals of pursuing academic and research careers in STEM (Roach and Sauermann 2017; Sauermann and Roach 2012), even as they continue in the program. Persisting in the field but changing the type of pursuit within STEM fits a "pathways" alternative to the pipeline metaphor. Although the distinctions between the terms of pipelines and pathways when referring to careers are not always clear (Fuhrman et al. 2011; Shauman 2017), here we use "pipeline" to represent attrition from STEM doctoral programs and "pathways" to consider, qualitatively, the movement toward post-degree career intentions within STEM. Examining the pre-doctorate change in career intentions is particularly important in the case of women in STEM, where their low representation among faculty and researchers limits the contributions of diverse perspectives and availability as role models for future scientists and engineers. We study this critical phase in the STEM career trajectory-the doctoral program-and focus on the physical sciences and engineering, fields where women's participation is lowest relative to men's. The present study makes a distinctive contribution by focusing on women in real time during the advanced stage of doctoral study, the requisite gateway to academic and research careers in STEM.

We followed female doctoral students over seven months and recorded events in their day-to-day educational, scientific, and personal lives, their reactions to these events, and the impact of what transpired on their view of themselves as scientists and researchers. We combined contemporaneous longitudinal data from online diaries and in-depth interviews collected over a period of several months. Women described specific incidents as they occurred, sharing details on the context, actions, and players involved in addition to their general attitudes and emotion that may be forgotten in retrospective reports. We explored what incidents, if any, influenced their identity as scientists and shaped their intentions and aspirations as researchers and members of the profession. We asked if there are incidents that made the climate welcoming or not, signaled discrimination, or indicated work-life imbalance that pose critical problems for women. We sought to understand what leads women to experience greater competence and identification as a research scientist, and what shifts interests away from academic science toward industrial research or other career paths that are not research-intensive. The reported incidents and meanings given reveal a dynamic unfolding over time of the women's conception of themselves in STEM fields. 


\section{Underrepresentation of Women in STEM}

It has been over 50 years since Alice Rossi first asked "Why so few?" (Rossi 1965) and an extensive literature on the underrepresentation of women in the science, technology, engineering and mathematics (STEM) fields followed. Involvement by several science organizations and policy makers signals the continued importance attached to answering this question (cf. American Physical Society 2015; Committee on Maximizing the Potential of Women in Academic Science and Engineering 2007; National Academies of Science, Engineering, and Medicine 2012; National Science Foundation 2016, 2017; White House Office of Science and Technology Policy 2016). While the proportion of women completing doctoral degrees in STEM fields has risen over the years, particularly in the life sciences and social sciences, these gains have been less apparent in the physical sciences where the proportion of women completing doctoral degrees in 2014 in the physical sciences reached $32 \%$, and only $23 \%$ in engineering (National Science Foundation 2017). Women of color represent an even smaller proportion of new PhD's, with less than $2 \%$ of doctoral degrees earned in the physical sciences and engineering (National Science Foundation 2017). The rate of completion of the doctorate for all STEM fields has not yet translated into numbers of women entering the academy or achieving tenure at research institutions, let alone advancing to full professorships and academic honors (Hill et al. 2010; Kaminski and Geisler 2011; Xie and Shauman 2003). Explanations for this disparity range from biological to institutional, economic to cultural with constructs such as the "leaky pipeline", "chilly climate", and difficulty "balancing" working and family.

\subsection{Gender Difference Explanations}

Several theories propose that women have selectively opted not to pursue STEM careers because of gender differences. As one explanation, women were viewed as having fewer attributes that lead to success in research-intensive science and engineering careers, such as quantitative ability, motivation, or background preparation. Although a growing body of evidence disputes the validity of this deficit model (see reviews and refutation by (Blickenstaff 2005; Etzkowitz et al. 2000; Spelke 2005; Sonnert and Holton 1995; Xie and Shauman 2003)), it lingers on in societal expectations, biased hiring choices (Reuben et al. 2014), and institutional cultures in environments such as Silicon Valley today. Alternatively, early theories proposed that women invest less human capital toward careers that require more effort and time because of anticipated lower return in wages and discontinuous participation in the workforce during childrearing and marriage (Mincer and Polachek 1974; Polachek 2004). The co-occurrence of career-building and childbearing "clocks" mean women more than men confront a demanding workload in establishing a research laboratory at a time of greatest fertility (Mason and Ekman 2007; Mason et al. 2013). This is compounded by women customarily assuming more responsibility for child-rearing and domestic chores than men (Hartman and Hartman 2008; Kmec 2013). Concerns that STEM work environments lack structural supports for family leave, flexible work schedules, and child-care, make them seem incompatible with career-life balance (Gibbs and Griffin 2013; Ivie and Tesfaye 2012; Moors et al. 2014; Tan-Wilson and Stamp 2015). The argument that women's choice to pursue family and child-rearing activities over career explains the underrepresentation of women in math-intensive fields (Ceci et al. 2009) has been raised. It has also been refuted by evidence that the decisions to leave STEM are influenced more by dissatisfaction with discrepant institutional and personal priorities than family factors (Glass et al. 2013; Levine et al. 2011).

\subsection{Sociocultural Explanations}

Social, cultural and institutional barriers such as discrimination and sexual harassment are another explanation for the poor representation of women in STEM. Although civil rights laws and other government regulations were enacted to make explicit discrimination less likely, some regulations have recently have been weakened, and a rash of sexual harassment revelations have shaken the sciences and public (e.g., Clancy et al. 2014, 2017). Informal practices of discrimination persist and discourage 
women, including women of color, from pursuing advanced education and careers in STEM fields (Gokhale et al. 2014). Women who leave faculty STEM positions cite lack of advancement opportunities and research support in the academic culture rather than family responsibilities (Xu 2008), supporting sociocultural rather than gendered explanations. Structural barriers such as access to fewer resources (e.g., Massachusetts Institute of Technology MIT) and the absence of critical mass of women in math-intensive fields and leadership roles operate largely out-of-sight (cf. Franzway et al. 2009). The larger disciplinary environment translates into local academic and workplace conditions and hiring practices that have historically disadvantaged women in STEM (Moss-Racusin et al. 2012; Reuben et al. 2014).

\subsubsection{Microaggressions}

Microaggressions are the daily, commonplace, often subtle acts and words that communicate slights and insults against members of a marginalized group (Sue 2010). For the perpetrator, microaggressions can be intentional and conscious or unintentional and unconscious, but nevertheless diminish and marginalize the target and become especially damaging as they accumulate and are internalized. Gender microaggressions may be delivered by well meaning others, what Glick and Fiske (1996) call benevolent sexism, i.e., attitudes that reflect gender stereotyping but are conveyed in a considerate and helping manner. In workplace settings where women are in the minority they report experiencing explicit or subtle discrimination more than their male coworkers (Gunter and Stambach 2005). Women are more likely to notice these offenses than men (Schumann and Ross 2010) and are aware of the negative impact on well-being and work performance (Basford et al. 2014). Alienating, negative workplace environments also lead to dissatisfaction in men and women, but the frequency and effects of gender-derogation are greater for women and cause them to withdraw from research-intensive careers (Settles et al. 2013).

\subsubsection{The Gendered Culture of STEM Graduate Education}

Particularly relevant to this study is research on the social, institutional cultures surrounding graduate education in STEM. Gunter and Stambach (2005) characterize university science departments as masculine cultures based on the interpersonal interactions typical of masculine norms, situated in a setting that promotes a "detached" "rational" approach to knowledge. Women entering historically male-dominated STEM fields face persistent stereotypes that foster marginalization and may trigger fears of negative social comparison due to gender (Good et al. 2012; Kiefer and Sekaquaptewa 2007; Logel et al. 2009; Smyth and Nosek 2015; Walton et al. 2015). For female students, university STEM programs are particularly "gendered organizations" given the high proportion of males in high-ranking positions (Britton et al. 2012; Fox et al. 2011; White and Ivie 2013), especially at the graduate level where the proportion of female students and faculty drops (White and Ivie 2013). Female doctoral students, even after already demonstrating competence as undergraduates, experience lower academic self-concept and low career commitment in male-dominated environments that lack mentor support and reflect insensitivity to family issues (Ülkü-Steiner et al. 2000). They perceive others as doubting whether their accomplishments are due to advantaged treatment rather than merit, while attributing their failures to individual deficiencies. Women in STEM feel they are held to higher standards than men (Concannon and Barrow 2010) and the expectation of being negatively judged increases their likelihood of leaving STEM (Beasley and Fischer 2012). In STEM doctoral study, where the research director's recommendations can be the key to a woman's future, the power differentials between students and faculty reflect and portend the extant power hierarchies in STEM professions and our society.

Gendered stereotypes and norms that place scientific-technical activities in the scope of masculine interests and outside the purview of feminine activity present barriers to women trying to attain an identity as a scientist in STEM fields (Carlone and Johnson 2007; Faulkner 2007; Ferreira 2003a; Merolla and Serpe 2013; Miller et al. 2015). Identifying as a female and a member of a traditionally 
male-dominated field deviates from or is incompatible with the norms for both (Cadsby et al. 2013; Danielsson and Linder 2009; Gonsalves 2014). Women of color in STEM graduate studies face additional stereotypes that run counter to the prototypical white male in science, what scholars have referred to as the "double-bind", further oppressing their identity as a member of science culture (Malcom et al. 1976; Ong et al. 2011). In a study of diary entries and attitudinal measures of entering female undergraduates, when STEM was viewed as incompatible with feminine identity, motivation to continue in science careers decreased (London et al. 2011). Lack of female role models and social support also decreased motivation for acknowledging one's identity as both a female and a scientist (Young et al. 2013).

Differences in communication style between men and women and notions of what is acceptable for women also present conflicts for women in STEM, leaving some caught in a "chilly climate" that is inimical to their styles and values. Wolfe (2012) and Wolfe and Powell (2009) found that a self-promoting style of communication typical in masculine contexts contrasts with a more collaborative communication style used by females. In a case study of female physics students, women described feeling limited in expressing feminine characteristics lest they risk exclusion from social interactions and academic experiences (Danielsson 2012). In another study, of women scientists, females devalued the expression of feminine characteristics in their women colleagues because of extant norms for neutral or masculine behavior in STEM environments (Rhoton 2011). Yet in contrast, women in these contexts experience negative repercussions for assuming a more self-promoting communication style accepted in men and may suppress their expressions to avoid further backlash (Moss-Racusin and Rudman 2010).

Entry into a profession involves not only acquiring knowledge but also developing an identity as a member of the academic and social community (Herzig 2004b). One of the greatest sources of opportunities to advance one's career is through stable social networks providing insider knowledge about how to succeed in the system (Etzkowitz et al. 2000). Through formal and informal connections, mentors introduce protégées to people who can answer technical questions, lead to other connections, and share precursory knowledge structures that help prepare and direct students. Instances of social interaction have been shown to impact women's self-efficacy beliefs and expectations about their success in STEM careers, even more than tangible measures of mastery and achievement (Zeldin et al. 2008; Zeldin and Pajares 2000). However, isolated from social networks, women often stumble in confusion about what to do and how to achieve, or leave because of missed opportunities (Etzkowitz et al. 2000; Xu 2008). According to Fox (2010), “More so than men, women may remain outside of the heated discussions, inner cadres, and social networks in which scientific ideas are aired, exchanged, and evaluated", (p. 1007).

\subsection{Theoretical Frameworks}

Theoretical constructs informed the present study in several ways. Persistence in a STEM career is a process generated from a series of interactions and the meanings given to the interactions that result in a trajectory of choices and decisions. In the present study, we draw from constructs of symbolic interactionism (Blumer 1969) to view events, participants' intentional actions, meaning-making reactions, and sequential social processes as templates for the data. In addition, constructs from identity theory (Carlone and Johnson 2007; Danielsson and Linder 2009; Gee 1999; Tonso 2006) provided a lens for designing the study and analyzing the data. Gee defined identity as becoming a member of shared social and cultural practices to become "the kind of person one is seeking to be and enact" (Gee 1999, p. 22). According to Carlone and Johnson (2007, p. 1190), one cannot enact a particular identity "unless one makes visible to (performs for) others one's competence in relevant practices, and in response, others recognize one's performance as credible". Enactment situations, such as conducting an experiment or presenting at a conference, form part of a socialization process with expectations for how to act and be recognized as a scientist in different situations. Tate and Linn (2005) found that women pursuing STEM careers integrated multiple identities from how they 
were perceived socially, academically, and intellectually by others. Experiences in one domain could impact another, as in a woman feeling uncomfortable socially and then engaging less academically. We draw from selected constructs of competence, performance, recognition, and the integration of multiple goals to examine the data for indicators of identity formation as scientists. We also consider constructs such as equity, discrimination, marginalization, microaggressions, and work/life balance to understand the social cultural characteristics of university STEM departments that may be experienced by women as favoring more masculine vs. gender-neutral characteristics. We extend these models to look for incidents indicative of scientific identity loss or gain, to see what happenings loosened or strengthened the participants' sense of themselves as scientists. Finally, we drew on the theoretical work of the [Authors' program] project of which our research is a part.

Research identifying reasons women veer away from STEM careers has primarily involved retrospective recollection through surveys or interviews with women after they decided to stay or leave STEM while undergraduates or in faculty positions. Few studies have focused specifically on what happens during doctoral studies, a time when following many years of coursework and preparation, women's science identity matures, or disintegrates, and her career goals become intentions. This present study provides a unique view of women's experiences during this pivotal period, in their own words and as they occur, to better understand the gender and social institutional conditions of graduate student life for women in STEM. We ask, what incidents in the day-to-day experience of doctoral studies strengthen or weaken a woman's construction of her identity as a scientist. We look for common characteristics among the incidents such as the players involved, the actions women take in response, and the meanings given to their experiences. We seek to understand what events or patterns of events might lead women at this final stage of their education toward or away from research-intensive STEM careers.

\section{Methods}

This qualitative study focuses on the reported incidents in the daily lives of the women in STEM during the advanced stage of their doctoral programs when doing their own research and/or working on an expert's research (their coursework largely complete). The units of study analyzed are defined as something specific that happens to a woman, an action that the woman takes, or her reactions or those of others. Incidents are not decontextualized but associated with events often common across participants, such as giving a presentation, seeking help from an advisor, interacting with lab mates, or struggling with an experiment. For example, when an experimental apparatus a woman has been working on breaks down (a happening), anger or discouragement may result (reaction) and the woman might endeavor to master the apparatus to prevent further problems (action). An incident also gains significance based on the reactions of others, such as when an advisor or co-worker reacts defining the breakdown as the result of the woman's clumsiness or poor scientific ability. Incidents may occur as part of a series. For example, if the breakdown is the fifth time the apparatus has malfunctioned, the incident becomes part of a pattern, social process, or narrative. Academic activities were important, such as conducting experiments, writing papers, or serving as a teaching assistant; but so were non-academic activities such as ordering supplies, getting access to special equipment, and community outreach. We were also interested in interpersonal interactions with advisors, other graduate and post-doctoral students, family, friends, networking and how these interacted with the women's professional activities. By focusing on incidents, we tried to capture the experiences that are easily overlooked in research comparing and contrasting attributes of persons or places. Rather, we wanted to understand the dynamic exchanges of person and context that contribute to the professional identity development of women.

Central to this qualitative study was the personal interpretation of the participants to notice, define, and remember a happening, or they would not have bothered to report it (Erickson 1986; Maxwell 2005; Saldana 2003). Participants reported incidents in interviews and through an online 
weekly post. Thus, what one woman defines as a disastrous halt to her scientific progress, another woman might regard as nothing more than normal routine (Blumer 1969).

\subsection{Participants}

Participants were volunteers solicited from disciplines of physical sciences and engineering where women are underrepresented (we excluded biological and social sciences since women are not currently underrepresented in those fields). ${ }^{1}$ The recruitment strategy was designed to solicit, concurrently, approximately 200 participants $^{2}$ for several studies that were part of the CareerWISE research projects on the experience of women in STEM doctoral programs (Bekki et al. 2013, 2014; Bernstein 2011; Fabert et al. 2011). We used information available from the National Science Foundation and the American Association for Engineering Education to identify those universities across the U.S. with the largest numbers of women doctoral students, regardless of race, ethnicity, or residency status, in the targeted fields. To reduce research expense and recruitment fatigue, and to maximize efficiency, we contacted the chairs of departments with 15 or more female doctoral students by email and phone. We asked chairs to distribute an informational flyer inviting participation in the various studies. Interested students contacted the project office directly to volunteer and staff provided additional details about the study. The final twenty-eight volunteers represented a self-selected sample, mostly white and domestic, who because of the criterion, were in research universities (primarily white institutions) with large enrollment departments. The ratio of men to women faculty in the departments represented ranged from 4.8:1 to 2.4:1. Women who agreed to participate completed informed consent forms indicating the results of the research study might be used in reports, presentations, and publications, but would not include identifying information associated with their names, institution, or department. Four participants were interviewed and submitted online entries; periodic online entries were collected from the remaining sample. One interviewee presented a conflict of interest, and another volunteer entered in her place. On completing the study, the online-entry participants received $\$ 50$ to $\$ 99$ and the interview participants received \$300 in Amazon.com credit. Table 1 provides a summary of demographic information about the participants, department/program majors, and the number who had male or female advisors.

Table 1. Participant Characteristics.

\begin{tabular}{lll}
\hline & $\mathbf{n}$ & $\mathbf{\%}$ \\
\hline Ethnicity: & & \\
Caucasian/White & 24 & $86 \%$ \\
Asian or Pacific Islander & 1 & $4 \%$ \\
African American & 1 & $4 \%$ \\
Hispanic & 1 & $4 \%$ \\
Multicultural & 1 & $4 \%$ \\
International Students: & 2 & $7 \%$ \\
Marital/Domestic Partnership Status & & \\
Single/Never married & 20 & $71 \%$ \\
Married/Living w Partner & 6 & $21 \%$ \\
Separated & 1 & $4 \%$ \\
Divorced & 1 & $4 \%$ \\
\hline
\end{tabular}

1 The research was conducted in accordance with the requirements for research with human subjects, and approved by the Institutional Review Board of Arizona State University on 1 September 2009.

2 Universities where research participants were recruited: Carnegie Mellon, Georgia Institute of Technology, MIT, Northwestern, Purdue, Rutgers, Texas A \& M, UC Davis, UCLA, University of Arizona, University of California-Berkeley, University of Central Florida, University of Cincinnati, University of Colorado (Boulder), University of Illinois Urbana-Champagne, University of Iowa, University of Massachusetts Amherst University of Michigan, University of Pittsburgh, University of Southern California, University of Texas Austin, University of Virginia, Virginia Tech. 
Table 1. Cont.

\begin{tabular}{lll}
\hline & $\mathbf{n}$ & $\mathbf{\%}$ \\
\hline Department/Major/Program & & \\
Engineering & 10 & $36 \%$ \\
Earth Science (geology) & 5 & $18 \%$ \\
Chemistry & 4 & $14 \%$ \\
Mathematics & 2 & $7 \%$ \\
Physics & 5 & $18 \%$ \\
Astronomy & 2 & $7 \%$ \\
Number with male advisor * & 33 & $87 \%$ \\
Number with female advisor * & 5 & $13 \%$ \\
Participants average age 27.4 (range 23-45) & & \\
\hline
\end{tabular}

* Both were checked in cases where there were co-advisors.

\subsection{Design and Data Collection}

\subsubsection{Interviews}

Three experienced qualitative researchers conducted semi-structured interviews based on ethnographic (Spradley 1979) and Cognitive Interview techniques (Moody et al. 1998). Interviewees served as informant and reporter of their experiences; and the interviewer elicited concrete details of the interviewee's experience, reactions, and the meanings given. Rather than focusing on success or discouragement per se, the interviewer asked participants to describe experiences or incidents, relate the details of the experience including the material and social context of the incident, the particulars of the incident, what happened before and after and what were her reactions. The interviews were semi-structured with the interviewer following the participant's answers to understand how she constructs her experience. The purpose of the study-to understand from her point of view what it was like to be a female graduate student in STEM-was repeated if necessary, especially at the initial stages of the interview. If the topic veered away from the purpose of the study, the interviewer guided the participant back. Interviewers asked for elaboration and detail to understand the actions and interactions that occurred, who was present, and what was the setting. A typical interview might start with, "Tell me about how things are going in any interesting things that have happened to you in the last couple of weeks." The interviewers remained neutral and nonjudgmental, focusing on the details of what happened and what the women thought about it. Clarification or elaboration was asked when needed, such as, "Who did and said what to whom? When this happened, what exactly did you say to your advisor? Where were your lab mates when this happened? Could you please describe/explain $\mathrm{X}$ in the language a layperson could understand? After an incident occurred the participants were asked questions like, "How did you make sense of it? What did it mean to you? Looking back over the incident, what, if any, effects did it have on you or your progress toward your degree, your situation or environment?" Participants were also reminded that they could make online entries at any time between interviews if they want to elaborate on material that came out in interviews or anything else.

The interviews conducted with each of four participants lasted 30-45 min, took place by phone or Skype approximately every two weeks over a seven-month period. The 10-12 interviews per participant were transcribed by a professional service and were archived to a secure location. The research team involved in data collection met to review the transcripts and ensure that the interviewers followed similar procedures.

\subsubsection{Online Entries}

The online entries followed similar methods as the interviews, however, participants themselves wrote about their incidents, with training and close monitoring to ensure that details were being provided. Participants were asked to make biweekly online entries reporting the details of incidents that occurred in the previous two-week period for the duration of the study. Project staff set up a 
secure website where individual participants could log in and make entries. Each participant had access to her previous entries, but not to other participants' entries. Training materials were available to help participants understand what we meant by an incident, including a catalogue of samples from interview transcripts obtained in earlier studies (Fabert and Bernstein 2009). We took care to balance encouraging and discouraging incidents in this catalogue, emphasizing that we wanted to hear not just complaints, but also the things that happened that participants perceived as positive. We also gave suggestions on the web site, such as paying attention to the sights and sounds of the place where the incident took place, noting who was present, noting what happened just before and just after the incident described. This was consistent with the principles behind the interviewing methods (Moody et al. 1998; Spradley 1979) as well as the qualitative, interpretive methods of research proposed by Erickson (1986). Similar data collection methods utilizing daily diaries (Niall et al. 2003; Travers 2011) and interval contingent diaries (Thoman et al. 2014) were effective in capturing the ongoing experiences, interest, and sense of belonging in undergraduate students. One of the research members monitored the online entries and when needed sent emails with follow-up questions to ask for more details and stimulate better responses; 233 emails of this type were sent. In all, 329 online entries were reported by 28 participants. Each online entry might consist of one or more incidents. A rough estimate of the number of incidents reported was over 500, although it was not always easy to disentangle a complex incident into component parts.

\subsection{Data Analysis}

Data analysis followed both inductive and deductive logic, with provisional hypotheses and constructs derived both from theoretical frameworks and from close inspection of the data. The identity model (Carlone and Johnson 2007) supplied the working constructs of competence, performance, and recognition and the working hypothesis that at least some incidents in the lives of participants might indicate a growing identification of themselves as scientists. The [Authors' program] framework suggested that incidents of chilly climate, gender discrimination, and work-life imbalance might occur and might lead to diminished identification as scientist. However, these constructs were merely working templates for considering the data rather than as testable hypotheses. Following inductive logic requires a close reading of the data, minimizing (to the extent possible) presumptions and biases and allowing constructs and hypotheses to emerge from the data.

Data generation coincided with data analysis, beginning inductively. Each transcript was read and coded for provisional constructs. Qualitative data analysis programs, e.g., HyperRESEARCH (2009), enabled this process so that the data passages from which each construct was developed could be connected digitally. Short memos that defined the construct allowed each researcher to follow the logic of the others. Round-robin discussions among the researchers online and in person promoted the clarity and consistency of analysis.

The initial analysis was aimed at general questions such as, "can incidents (action or occurrence and reaction) be identified?" Do incidents form a social process (Blumer 1969) or lead to some kind of consequence? How might incidents be characterized or typified or otherwise grouped together? For example, we found that incident types included encounters with advisors, interactions with peers, presentations, interpersonal conflicts, asking for assistance, emergencies of family or friends, and so on. We also sought to characterize participants' reactions to incidents, such as with joy, indignation, trepidation, realization to persevere or withdraw, renewed effort, and the like. It is important to emphasize that our questions and methods focused on the incident as the unit of study compared to most qualitative or quantitative studies where participant or subject are the unit of study, writing case studies about persons or drawing conclusions about typical persons. Instead, we focused on how incidents become patterns revealing processes transferable across participants and to other women in similar conditions. The sample was too small to compare differences between women by racial/ethnic identity. 
Initial codes labeled the general context of an incident, such as working on an experiment, writing a paper, asking for assistance, and helping others. The codes branched to focus on the actions, interactions, and reactions of the participant and others involved. For instance, in one instance a participant might view helping others as a sign of growing confidence in being able to explain her work to others, while in another, the participant might view helping as something she is expected to do more than men, and experiences it as a burden that interrupts her progress. In another example, getting assistance might involve interactions where she gets assistance, or not, or is even reprimanded for asking. The initial coding stayed close to the data in level of inference, yielding numerous codes often common across incidents and the participants. Some incidents, such as an advisor's departure, were mentioned several times but only by a couple of participants.

The deductive analysis drew on chosen conceptual frameworks and asked, how (if at all) does each incident reflect the constructs proposed? Each transcript and online entry was read and reread with the constructs in mind. The science identity model (Carlone and Johnson 2007) became a kind of template for considering the data and joined the provisional constructs and hypotheses that had emerged inductively. How might a given incident indicate the constructs of competence, performance, recognition, growing or diminishing identification, cultural and institutional or social structure, microaggressions, or work-life balance? This part of the analysis followed the method of modified analytic induction (Erickson 1986), induction and deduction in constant dialogue to develop warrantable assertions that emerged from the data and stood the test of coherence and plausibility. We asked, for example, if a preliminary assertion was backed by sufficient quantities of data and data derived by different data generation methods? If not, it should be discarded or else revised until it did. In our study, the characterization of incidents that emerged from interviews did not diverge from that of the online incident entries. After a systematic search for data that disconfirmed an assertion, we considered an assertion to be warranted if the weight of the accumulated evidence supported it. The resulting data and assertions were circulated among the authors to make sure of coherence across data sources, researchers and evidence. Although qualitative analysis does not usually count the qualities that it uncovers, we attempted some very rough numeric estimates of the categories we uncovered. We differentiated whether a particular incident happened rarely or often or somewhere in between using the terms: "typical" meaning most participants reported a similar incident; "frequent" when many participants reported a similar incident; "few" when five or fewer participants reported an incident. Readers are cautioned, however, to consider these estimates as relative indicators only. A single event or a series of events and situations could steer a woman toward a different path.

Our intent was to stay as close to the participants' voices and points of view as possible in their detailing of incidents. Thus, we report segments of text that support our findings, quoting their words to the extent possible. However, our primary responsibility is to protect the identities of the participants and make sure that the information they provided could not be associated with individuals. This responsibility required that we obfuscate some details and narrate what would otherwise (in studies with less identifiable groups such as undergraduates) have been reproduction of their exact words. This was a particularly stringent requirement because the scientific research projects the participants were engaged in were highly specialized activities that might be readily identified by people in the same field. Excerpts were chosen to illustrate common themes in the incidents shared among the women rather than a study of the women as individual cases.

\section{Findings}

\subsection{Many Incidents Increased Recognition of Self as a Scientist}

Science research is a practice that depends on the development of scientific expertise and socialization toward a career even while confronting problems and uncertainties that are inevitable in the scientific process. Many incidents marked increased competence, performance, recognition and positive identification toward self as scientist, supporting the Carlone and Johnson (2007) model 
of developing a science identity. By selecting 4 th and 5 th year doctoral students we nearly assured competence from the beginning, as they all had completed their graduate coursework and some had completed or were completing examinations during the period of study. Many were working on the research studies of their advisors, some were already working independently, and several had already published the results of their studies. At this stage in their doctoral studies the women in our study were trying to prove themselves to be successful scientists with a place in the field.

\subsubsection{Demonstrating Competence}

Prototypical incidents of confronting problems and uncertainties often increased confidence and served as turning points in the process of identifying oneself as a scientist-in-the-making. Inevitable setbacks in the scientific process could be disrupting but most women in this study interpreted them as challenges and opportunities. Successes along the way, even small, could be turning points strengthening initiative and resolve. Conducting an experiment, helping on a research project, realizing the potential for a program of research all her own, explaining her work to others, were informal marks of growth. After many false starts, Barbara exclaimed, "I'm growing usable samples! By myself! I'm encountering challenges, thinking thoughtfully and carefully about them, and solving them! It feels fantastic!" After spending a month constructing a novel piece of equipment that finally worked and began producing data Brooke wrote, "This is the first time in quite a while (maybe since entering grad school) that I feel like I've really done something 'right' in the lab. I'm starting to feel more confident and more hopeful now." Eva described, "feeling that excitement about an experiment that I had planned and worked so hard to get to made me realize that in some way shape or form I do want to do science with my life." Mastering challenges brought the realization of being a scientist and strengthened resolve to continue in the field.

\subsubsection{Recognition by Others}

Interactions with advisors, faculty, and peers contributed to a sense of being recognized by influential others in STEM. For instance, when an advisor asked a student to read some papers and then together worked through the issues as colleagues, she felt more like a scientist and confident in her abilities. Throughout the data the women used similar incidents to develop a forward momentum and eagerness to progress. Progressing on the trajectory from novice to expert included helping others learn. Lynn felt recognized when she was able to help the more junior students in her lab, "I'm stepping up on the ladder now, and I can help others who are struggling with the first rungs." Yolanda felt recognized by hearing her work referenced by another speaker at a national meeting, and wrote:

The best part was when I walked into another talk by a professor from another university. His entire introduction he showed graphs, figures, and other data from a paper I published a few months ago. Then, he referenced my work, quoting that it was a 'fantastic paper' that the audience should read. He then proceeded to describe his research, which was based on my publication. It was incredibly rewarding to hear what other members of the scientific community thought of my work, which makes me feel very proud.

Cheryl valued her advisor recognizing her performance. She described proving she was right when her advisor did not believe her findings, spending two days thoroughly rechecking her work after he questioned it. She made sure her advisor recognized her too.

Everything turned out to be right. I went back to him and said, 'This is right and this is why you can't see it.' He said, 'Okay, you're right,' then he started to keep talking. I said, 'Wait a minute, can you stop for a second? I just want to revel in this moment,' and he did. So, I convinced him, and that was good. If I can convince him, then I convince myself that what I'm doing is right. 


\subsubsection{Presenting and Publishing as Performance Markers}

Recognized as important for professional identity and socialization, the participants described several incidents marking their performance by presenting papers and conference presentations. Even presentations to department meetings and research seminars were occasions to mark progress. A number of incidents were reported that suggested participants used such opportunities to clarify their thinking, practice their presentation and question-answering skills, and get feedback that they were doing interesting and valuable work. In each instance the women marked the occasion as propelling them along on a trajectory toward being a scientist. They seemed to identify with the larger enterprise of which they were becoming a part. For example, Brooke was excited about her experience presenting a paper at an international conference. She valued the possibilities to network and to meet the "giants" of her field as well as other researchers who are "actually worrying about the same small part of the universe as me." Clara pronounced herself "giddy with excitement" and hopeful that her research was on the right path as a result of her presentation at a national lab.

Besides conference presentations, the publication process, though often frustrating, marked and enabled students' progress. Many participants were well into the process of developing and submitting manuscripts for publication. For example, on receiving notice that her paper was accepted for publication, Clara wrote, "I submitted my revisions, and it's now in press! It's great to finally have my name on something." Lynn said her co-authored publication, "shows I've dedicated work to the experiment, and therefore I'm considered a member of the collaboration." Conducting research and submitting manuscripts is replete with setbacks, mistakes, and disappointments, yet the participants shared several incidents of their perseverance and achievements, through which their view of themselves and recognition by others that they were becoming capable members of their fields grew.

\subsection{Many Incidents Were Suggestive of a Social and Academic Culture Alienating to Women}

Although some incidents and subsequent reactions illustrated a sense of smooth sailing, this was not always the case for our participants. Many incidents suggested a social environment that was alienating and less than supportive for women. Discouraging experiences both subtle and not so subtle were common and evoked palpable reactions in the participants. In the analysis, we had to expand or look outside the identity model to account for these incidents to a larger social structure and culture. The incidents included actions that were deprecating, hypercritical, distant, arbitrary, and condescending. They involved interactions with professors, scientific co-workers, post-docs, and fellow students. The women's reactions included feelings of exclusion, vexation, loss of confidence and low morale. In some instances, women did not let these experiences interfere with their identification with science, but at other times the identification seemed to diminish.

\subsubsection{Too Few Women}

One of the primary conditions in STEM workplaces concerns the sheer disproportion of males to females in the work and academic spaces, described by other researchers noted earlier in the paper and evident in our sample. Of the 28 combined case and incident study participants, only five indicated that they had a female advisor or co-advisor, and almost all participants believed there were not enough women faculty in their program. Very few instances in the data record involved the participants interacting with female peers in their work places, although some incidents refer to women post docs, lab researchers, and even a few faculty. Most of the participants sought female contact outside their labs, for example in women's committees and social groups. Participants described incidents where they were overlooked for training or their efforts were used to help others, but since there were few women to turn to for validation or support, their concerns were not acknowledged as important. The preponderance of men made for masculine cultural and behavioral norms in STEM academic settings, such as a more self-promotional and aggressive style of communicating, way of dressing, and focus on objectivity and activities already considered masculine such as technology (Ferreira 2003a; 
Gunter and Stambach 2005; Miller et al. 2015; Wolfe 2012), that could leave women feeling isolated, alienated, lonely and different.

Expressions of uncertainty and emotionality were feared as deviating from masculine norms and lessoning one's identity as a scientist. Participants complained of lack of empathy for personal or family problems, or that they were the only ones in their group providing emotional support for other students in distress. Tori was recovering from a period of grief following a death in her family and hoped to finally have a good conversation with her advisor about where her project was going until the following occurred:

He really tore into me. But he really crossed a line when he brought my family into the discussion, which he does every fucking time he doesn't think I'm motivated enough. He referred back to my 'down time.' He claimed he 'understood' my lack of productivity following what had happened, but then went on to elaborate that another significant amount of time has passed and I'm still floundering. He let me know how I was doing the worst out of the group at the present time. Wow, what an inspiring speech. That just made me want to run out and work real hard. This is when I started crying and didn't stop for the rest of the $15 \mathrm{~min}$ of the meeting. I couldn't stop it. Then after the tears fell for a few minutes while he was yelling at me, he got me a tissue and said 'Geez, you're crying, you must think I'm being really hard on you.' It was so humiliating. If you show any weakness, they eat you alive.

When her advisor did not acknowledge his harsh way of communicating and minimized its negative impact, Tori felt he viewed her as mistaken and oversensitive when she ended up crying. Not having female faculty or mentors to discuss how to communicate concerns such as family problems made handling situations like this more difficult. When Brooke faced a situation involving harassment she wished she had a female to advise her.

I don't feel comfortable discussing this with my advisor or with any of my male professors. I emailed a female mentor of mine for her advice, but really wish that I had someone here-a woman professional that I had a good relationship with and who I felt would be understanding, sympathetic, and have good advice-to talk to in person.

Anita would have liked more women to talk to and model how to speak up without being misunderstood or viewed as too demanding,

I don't know how to be proactive without crossing the (most likely only in my mind) line into aggressive, unattractive behavior. In my research environment there aren't many women who I can talk to this about.

\subsubsection{Aggressive Communication}

Incidents of excessively critical, boasting or argumentative communication, more characteristic of the self-promotional communication style typical in masculine communication (Wolfe 2012) made several of the participants uncomfortable. This occurred in formal and informal settings and was interpreted as aggressive and needlessly harsh. Cheryl described a male professor who had recruited her to the university, then retaliated against her after she chose someone else to be her advisor. Brooke described a conference that involved,

... a lot of grandstanding during talks and during the posters, a lot of jerks walking around and indiscriminately ripping on posters and the poor innocent grad students (and some undergrads) presenting them.

Dismissive treatment and critical remarks occurring within the context of lab meetings with other students and faculty were especially hurtful. That these incidents happened in the presence of others 
who said nothing suggested a climate where communication that defies group norms was inhibited, which can have the effect of silencing those in the minority. Leah described an incident where she felt diminished by a senior lab mate and her advisor not intervening:

I was trying to present a model for a fundamental reaction in our field and John just laughed at me. Laughed at me. I didn't know that many people in the field have tried to solve this problem. All he said was, 'that will never work.' And my advisor knew I was upset because I just sat there silent and got out of the meeting immediately when it was over. But he didn't say anything about it to John.

A more personal experience of dismissive, interrupting, hostile and demeaning communication was described by Barbara during her preliminary examination:

I started my presentation feeling confident, standing tall. I wasn't even halfway through reading the title before they were both on their computers and iPhones- they missed my entire motivations, vision, and talk outline, in which I articulated the importance of my thesis. I didn't know what to do- I started by explaining the phenomenon I had observed, the mechanism that caused it (which I said I would later prove by means of a model), and how this phenomenon affected the data. 'Why are you showing those two pathways? Are there other pathways?' Jack, a committee member, asked. 'What are the probabilities of those pathways? How do you know it's those two and not any other pathways?' I told him I would explain in a bit, but they interrupted. 'What you should have done was present the raw data first, and then ... ' he continued for a bit about how I should have laid out my slide. I finally got to my model after $45 \mathrm{~min}$ of constant interruption. 'The model has excellent agreement with the data,' I said. They immediately pounced-'I wouldn't say that, what about those data points on the edges? What you should have done was zoomed in on this peak...' It continued like this for a while. Jack got up from his chair, takes the laser pointer from me, and begins on one of his tirades: 'what if you gave this to your 9-year old sister? And told her to connect the dots? What would she do? She'd go from here to here to here, and then what? Down here? Up there?

Barbara's advisor stepped in at this point to defend that her data fit her model and point out that the reviewers of her already published paper had noted it as a strength. However, Jack was unimpressed. Barbara felt her attempts to redress his concerns were discounted and she had no recourse but to endure the verbal attacks:

And I just stood there. I tried to stand tall, but I just stood there. What else could I possibly do? I couldn't move on, I couldn't interrupt him. I wasn't answering his questions satisfactorily. I couldn't possibly win. So, I waited for him to finish, every time he got out of his chair to criticize my data. Every time I said what I thought the data was suggesting, the two of them would snicker.

The critical and aggressive communications were experienced as hostile and demeaning by some of the women in our study. Although male students were also reported to sometimes get harsh feedback, the criticisms did not have such gendered, child-like connotation.

\subsubsection{Competition over Collaboration}

Another quality of a masculine culture was an emphasis on competition over collaboration experienced by some of the women. There were instances where achievement was used to instill animosity and competitiveness among fellow lab members. When a male international student had trouble presenting his research, Cheryl tried to help by asking questions to make his research clearer. She described how her advisor, "said in front of everyone, 'Why is Cheryl having to give your presentation for you? How come Cheryl knows this and you don't?'” Cheryl described thinking, 
“'Don't do that to the guy', I felt terrible", The criticism showed disrespect for the presenting student but, to Cheryl, also implicitly communicated that women were not expected to do better than men.

The pressured striving to beat others at producing scientific research was another competitive aspect of the culture. Scientific research often involves the effort of many, with advisors and post-doctoral researchers sometimes using students to advance their own research interests, even as the students' own progress is deterred. Teresa's advisor frequently pressured her for results, impatiently questioning her commitment and "expecting her to drop everything" to finish his experiments. Although she attributed some of this pressure to his being untenured, his impatience still discouraged her from a future research career in academic research. As Teresa explained:

Everything is an emergency. Sometimes he would be afraid that we would get scooped or something, like someone else would publish a paper similar to ours, so he wants to do everything as fast as possible. I can sort of understand. What I'm working on is, I guess, a pretty competitive field. But, I don't know, I kind of-I guess, like that ASAP doesn't really mean much to me anymore. I think it has a lot to do with being a new faculty member. He really needs to get out publications and get his reputation.

\subsubsection{Microaggressions}

Direct and indirect microaggressions communicating that women are unwelcome and do not belong were reported in the day-to-day interactions with classmates, advisors, post-doctoral and visiting researchers. Participants perceived these subtle or not so subtle messages as devaluing their ability as scientists or in some way communicating inferiority. Sometimes the message was direct and clearly associated with gender, but other times it was unclear but attributed to gender. A large number of these interactions resembled the taxonomy of direct and indirect microaggressions that have been previously identified by Sue and others (Sue 2010; Sue et al. 2007).

Some of the most common microaggressions were subtle messages invalidating the participants' membership by ignoring them, meeting without them, or leaving them out of social events. When this happened, the women felt less valued in their lab or peer group, not important enough to be missed, and their contributions unrecognized by their colleagues. Leah described feeling overlooked in scientific conversations:

Jerry loves to ask John about his latest findings and John loves to tell him about them. He loves to write his reactions on the board and go over them. They treat me like I'm not there. They never include me in the conversation or ask my opinion about anything scientific. They treat my experiments like they are trivial. And I have as many publications as John and more than Jerry does, even though they're a year ahead of me.

Being left out of social interactions like invitations to lunch also left participants feeling alienated, or, if invited, not wanting to be the only female in a mostly male-oriented social interaction. Linda felt left out after lab meetings when not invited to go drinking with the post-docs and other lab-mates who were all male, but also reported that she would not have wanted to go anyway. Teresa felt invisible when her lab mates reverted to speaking Chinese when her advisor was not around. Anita described one male lab mate asking the other if he wanted to get some lunch,

... then they said goodbye to me and left! They did not ask me whether I would have liked to join them. I never feel quite right inviting myself-whether it is to lunch or asking to go to a conference.

Of interest is that our informants focused on the discomfort associated with not being included, but did not speak to the disadvantage that stems from being excluded. Informal social gatherings can comprise missed opportunities for women to engage in professional conversations that lead to collaborations, nominations, and new directions. Not being included contributes to challenging a sense of belonging (Good et al. 2012) that is important to science identity and persistence. 
Another kind of subtle message was being asked to do "women's work". This could involve taking care of others, assuming the role of "lab mom", non-research activities such as science activities in the community, cleaning up the lab, and tasks that would be considered clerical. Teresa was frustrated at repeatedly being asked to order supplies for the lab.

The post-doc asked me to place an order, which I have done before. This requires getting a PO number from the department office before sending it in. So, I placed the order and asked for the number. I wish I just sent him the form and told him what to do. Instead of him just placing the order and asking for the PO number, I placed the order and now have to bug the person to get it. It's frustrating to me that he doesn't just ask how to do it, but for me to do it.

Several incidents involved situations where participants were given feedback seen as implying they were incapable in general, rather than addressing specific areas in which they might benefit from assistance. For instance, Ruth reported that her advisor complained when she took time to get the statistics correct in a study she was reviewing, and instead of helping her with her questions told her she should look for a different advisor who specialized in statistics, which she interpreted as implying she was incapable of working with him. The women were inclined to blame themselves for others treating them dismissively. Linda described how a student ahead of her in the program asked about a calculation but disregarded her answer, leaving the impression he assumed she was inferior and not expressing herself well:

I was trying to come up with an explanation but Rick just said no and closed his eyes. I think that this is also something that happens often with my group, that they think I am wrong when I am not, but I am just not expressing myself well, or just not doing things the way that they would.

Another form of microaggression was discounting merit and achievements. Several of the women in the study competed and won fellowships and awards, which were greeted with the perception among others of reverse discrimination. Some of these awards were designated for women, but not all, yet there was a common concern that their colleagues attributed all awards to affirmative action rather than merit. When Yolanda's advisor commented she was on a "lucky streak" when she was nominated to attend a prestigious conference for top faculty and students in addition to other awards and honors she had already earned, she interpreted it as disparaging her abilities and effort. Patricia also experienced this disparity when she talked of competing with a fellow male student for a scholarship, and that no one would believe her success was due to merit and not preferential treatment:

If he got a scholarship that I did not, I was supposed to be very happy for him and excited and celebrate. But when I received a scholarship that he didn't get, he blamed it on the fact that I was a woman and that they probably gave me the scholarship to fulfill a quota of minorities in science and engineering!

\subsubsection{Overt Sexism and Sexual Harassment}

Contributing to a demoralizing atmosphere for women were some incidents of overt sexism, discrimination, and harassment. Participants were acutely aware of and sensitive to such events occurring to women they knew or knew about, or events that had happened to them in the past. The personal impact was enhanced by a sense of no recourse and fear of being stigmatized if others in the labs knew. Over the seven months of the study, three incidents of sexual harassment were reported. In one case, Brooke discovered that a man who sexually harassed her at a conference several years before would be in attendance at an upcoming one, making her afraid to attend it lest he would come to her talk. Brooke recalled:

I was 20 at the time, very naive and trusting, and he was probably in his mid-60's, married and almost old enough to be my grandfather. The whole experience really freaked me out 
and I ended up sitting alone in my hotel room with the doors bolted for the rest of the conference to avoid seeing him. Later, at my Dad's insistence, I filed a formal complaint against him, but nothing came of it. Just seeing his name on the list made me feel sick to my stomach, and just thinking about this has me more freaked out and nervous and physically distressed than quals [qualifying exams] ever did. My first talk at a conference will have me nervous enough, and I don't think I can do it knowing that he is lurking around. I am afraid of what my professors might think about me if they found out about this. I know that many of them (as well as even many of my female friends) feel like most sexual harassment complaints are exaggerated and overstated and that the women who file them are just being oversensitive and bitchy.

Cheryl recounted derogatory comments made by an older male faculty that implied the interactions of a female student and male professor were sexual:

She has a really very close good relationship with a professor. A healthy relationship and they talk a lot about their science. They are always in each other's offices talking. In their office is another professor who is one of those 'old school, good old boys' and he's completely your typical sexual harassment pig. Every time he would walk by their office and see them talking he would say, 'You know, guys, you spend an awful lot of time together, this is how rumors get started.' And he would comment on her makeup or her cleavage. It's crazy. It's ridiculous.

Cheryl recommended that her fellow student report the harassment, but they both regarded the process with pessimism. They felt that not only would such complaints create negative reaction by the department, but that those they knew about went on forever and never came to anything, indeed were the source of embarrassment and ill-will against the women who brought them. Sexist remarks were embedded in the culture and reminded women that others sometimes regarded them through gendered stereotypes. Carol described how a thoughtless comment reminded her that sexual stereotypes could prejudice her male peers:

[A male student] sent a joking email reply to the whole lab (all professors excluded, fortunately) in which he indicated that he wanted to see me (though with a code name) in a bikini. I know that this student didn't mean anything by it—he even apologized to me before I had seen the email. Still, though, it just served as a reminder to me that no matter how well I do or how much my work is respected, I'm still "different" and some guys still see things in terms of gender.

Sexism through tokenism, where outnumbered women and minorities are considered not as individuals but as representatives of their groups (Kanter 1977), was a theme that emerged in some incidents. Some participants doubted the sincerity with which department heads and professors took gender into account. Some believed that researchers who apply for grants must give lip service to women's issues or the granting agency would not look favorably on their proposals. Yolanda came across an email from a faculty member in her department that suggested insincerity and lack of conviction for recruiting diverse students:

My PI [principal investigator] forwarded a string of emails \{about\} giving lab tours to a program that tries to encourage women, minorities, and underprivileged high school and college students to pursue science. The tone was overall indifferent (at best) towards helping out these program participants.

Tori felt singled out based on her gender:

Since I am currently the only female graduate student in my group, my advisor has told me that I have to recruit women ... he has not told anyone else to do this, just me. I am given 
the duty to take any female recruits that visit out to lunch and entertain them and while this may seem flattering that my boss trusts me enough to recruit, I only ever do whenever it is a FEMALE recruit. The same thing happens when we host speakers; he has a group of his favorite guys that go out to eat with the speakers, and the only time I ever get asked is if it is a FEMALE speaker.... it's a little insulting to be paraded around as the token female.

There were examples where concerns that are especially significant to women, such as issues that might be associated with health and childbearing risks were discounted or magnified as personal. At a group meeting discussing the risks to fetuses posed by some of the chemicals, for instance, Teresa described feeling singled out by all of the group members turning to look at her, the only female. Leah reported becoming concerned about radiation safety after reading the manual on the apparatus she was using for her experiments. When she told her advisor about her concerns, he looked at her as if she were crazy and scornfully told her he would bring his baby into the lab. She felt embarrassed and infantilized.

The masculine culture can be a source of discomfort and demoralization and was sometimes mentioned as a "push" to get out of science. With few exceptions, women did not resist because, as Tori noted, "my whole future depends on the letters of recommendation they write." That men in the middle of the culture fail to recognize it as such and often assert that the environment is gender-neutral corresponds to the denial of sexism identified in the taxonomy of microaggressions by Sue et al. (2007).

\subsection{Balancing Work and Life Was Sometimes Difficult}

The challenge of combining work and personal life is hypothesized to be an important determinant of gender imbalance in STEM (Bernstein and Russo 2007; Mason et al. 2009). The incidents in the present study elaborate this interpretation. Several existing studies document the decline of the proportion of women in physical sciences and engineering between the time they complete doctoral programs and when they would logically begin academic research positions (Ceci et al. 2009; Gibbs and Griffin 2013; Hartman and Hartman 2008; Ivie and Tesfaye 2012; Kmec 2013; Mason and Ekman 2007; Mason et al. 2013; Moors et al. 2014; Tan-Wilson and Stamp 2015). It has also been argued that women's period of fertility coincides with the time to build their research portfolio, and that coincidence is responsible for women leaving research- intensive careers to pursue a desire to build their families.

Only one participant in our study, Cheryl, was currently raising children during graduate school. Several of her incidents involved both the disruption of her training caused by caring for her children, and the interruption to raising her children caused by her graduate training. She described having to forego social events, conference participation, and delays in the completion of her research because of caring for her children. She also feared she would not compare favorably against students without these circumstances. Cheryl did not hope for special status as a mother, but just opportunities to progress in a way that would accommodate her situation, unique as it was compared to others in her program:

You lose the opportunity to do your networking, to talk to other scientists, to show your work, to get feedback on it, and to basically, in some way, socialize with your peers. You might notice on a CV that you don't go to as many conferences that you normally would if you were not with family and married. I would assume it does make a difference, and if a woman and a man are both competing for the same job, these holes are going to show. I have to do what I have to do and hope for the best and that people will understand.

Many women in the study began to recognize the possible future interference between a research-intensive career and family formation. They spoke about the potential conflicts ahead and decisions that might have to be made. Patricia wrote, "I get the distinct feeling that staying in academia means sacrificing family life because I don't have time to do anything else but work." Realizing this made her wonder whether a job in industry might be a better option than a research-intensive career for balancing career and children. Some women worried their biological clock will run out before they 
could establish their careers. For example, Anita would read on Facebook or hear from her mother, "that people I went to school with are getting married, buying houses, having kids, getting a great promotion at work. I feel like life is passing me by." Ruth believed that having an academic career and a family was harder for a woman:

If I were a guy, I could take a chance to start an academic career and sacrifice another 10 years but if I want to have children, I can't spend another 10 years working as much because I would be 40 and it's late to start thinking about founding a family. So, the main gender difference comes into play right now: what do I want most? Career or family? and where I'm standing now the two seem to be incompatible.

Leah, in addition, wrote of the physical barriers she perceived as a woman studying chemistry:

In the organic chemistry labs, we can't become pregnant and continue working in lab because of the chemicals we deal with. Not to say I want kids now, but what if I did? I couldn't have them without significantly delaying my graduation (or not graduate at all!) and I'm pretty much stuck having to wait until I'm in my 30s to even start thinking about starting a family.

Other problems of balance emerged from families of origin, romantic relationships, and friendships. Many incidents reflected the effect of a romantic partner as a distraction or pull away from participants' research trajectory, consistent with Mason et al.'s (2009) findings that a third of women PhD students cited partner issues as a reason for veering away from research intentions. In our study, the research work of participants was often interrupted and delayed by incidents that involved attending to or leaving relationships. For example, during the study, Yasmeen separated from her husband and had to deal with problems of living quarters and finances, which took away time and energy from her research. Melanie reported a discussion with her advisor about her completion schedule (the average in program is six years and she wants out in five). "But I DON'T want to be here that long! I want to get married and find a job wherever my boyfriend gets his." Danielle wrote about balancing her relationship:

Getting married is probably a second factor in my goals too. Because it's a long distance relationship right now, everything I have has an emphasis of 'quick!' to it. My overall goals for getting high impact papers or maybe just a ton of papers out has decreased significantly. I kind of just want the 3.0 GPA version of a PhD.

Many incidents reflected the recurrent need for sociability, communality, familial relationships, interdependence, reciprocity and affiliation. Life was meant to be more than the laboratory, more than the individualistic, competitive, hard-core narrow focus on one's research. Lynn planned to leave the field if it becomes necessary to live in a place away from her family and friends. Three participants got engaged or married during the study.

In a survey of PhD students at the University of California, $46 \%$ of women, compared to $21 \%$ of men, cited issues related to children as a reason for shifting away from research faculty careers (Mason et al. 2009). Our participants, save one, had not personally confronted the difficulties involved in simultaneously doing research-intensive work and raising children.

The following tables (Tables 2-4) list some of the incidents mentioned and the frequency in which they occurred in the data. Incident frequencies are estimated. Typical $=$ most participants reported a similar incident; frequent = many participants reported a similar incident; few $=$ five or fewer participants reported an incident. 
Table 2. Incidents that Increased Recognition of Self as a Scientist.

\begin{tabular}{|c|c|c|c|}
\hline Category and Codes & Typical & Frequent & Few \\
\hline \multicolumn{4}{|l|}{ Demonstrating Competence } \\
\hline Collaborating with and helping another student & $\mathrm{x}$ & & \\
\hline Making progress on a project, experiment & $\mathrm{x}$ & & \\
\hline Surmounting equipment or research problems & $\mathrm{x}$ & & \\
\hline \multicolumn{4}{|l|}{ Recognition by Others } \\
\hline Getting nominated for an award & & $\mathrm{x}$ & \\
\hline Advisor/peers compliment her research work & $\mathrm{x}$ & & \\
\hline Requests for assistance responded to with respect & & $x$ & \\
\hline Others referencing her work & & $\mathrm{x}$ & \\
\hline \multicolumn{4}{|l|}{ Presenting and Publishing as Performance Markers } \\
\hline Presentations to department meetings & $\mathrm{x}$ & & \\
\hline Presentations to conferences & $\mathrm{x}$ & & \\
\hline Publications & & $\mathrm{x}$ & \\
\hline
\end{tabular}

Table 3. Incidents Suggestive of a Social, Academic Culture Alienating to Women.

\begin{tabular}{|c|c|c|c|}
\hline Category and Codes & Typical & Frequent & Few \\
\hline \multicolumn{4}{|l|}{ Too Few Women } \\
\hline Lack of Female Mentors or Role Models & $\mathrm{x}$ & & \\
\hline Few opportunities to socialize with female peers & & $\mathrm{x}$ & \\
\hline \multicolumn{4}{|l|}{ Aggressive Communication } \\
\hline Ignored, interrupted when talking to others & & $x$ & \\
\hline Laughed at while speaking & & & $\mathrm{x}$ \\
\hline Critical references to faults, slowness of her work & & $\mathrm{x}$ & \\
\hline \multicolumn{4}{|l|}{ Competition over Collaboration } \\
\hline Public comparisons to others & & $\mathrm{x}$ & \\
\hline Others taking credit for her work & & & $x$ \\
\hline $\begin{array}{l}\text { Pressured by others to produce results on an } \\
\text { experiment, finish a paper, etc. }\end{array}$ & & $\mathrm{x}$ & \\
\hline \multicolumn{4}{|l|}{ Microaggressions } \\
\hline \multirow{2}{*}{\multicolumn{4}{|c|}{$\begin{array}{l}\text { Not invited to social events (e.g., going out to } \\
\text { lunch, happy hour) }\end{array}$}} \\
\hline & & $\mathrm{x}$ & \\
\hline \multicolumn{3}{|l|}{ Ability questioned rather than getting specific help } & with a problem \\
\hline \multicolumn{4}{|l|}{ Achievements discounted or attributed to } \\
\hline \multicolumn{4}{|l|}{ affirmative action rather than merit } \\
\hline \multicolumn{4}{|l|}{$\begin{array}{l}\text { Assigned stereotyped tasks (e.g., ordering } \\
\text { supplies, picking up parking passes for guests) }\end{array}$} \\
\hline \multicolumn{4}{|l|}{ Overt Sexism and Sexual Harassment } \\
\hline Expected to represent women & & $\mathrm{x}$ & \\
\hline Sexual physical references made about her & & & $x$ \\
\hline Unwanted sexual advances from another & & & $x$ \\
\hline Witnessing another woman get harassed & & & $x$ \\
\hline
\end{tabular}

Table 4. Incidents of Work and Life Balance Difficulties.

\begin{tabular}{lccc}
\hline Category and Codes & Typical & Frequent & Few \\
\hline Concerns about managing a STEM career and family in the future & $\mathrm{x}$ & & \\
Sacrificing time with family/partner to complete work & $\mathrm{x}$ & $\mathrm{x}$ & $\mathrm{x}$ \\
$\begin{array}{l}\text { Sacrificing work to accommodate time with family/partner } \\
\text { Changing major or discipline to accommodate family }\end{array}$ & & \\
\hline
\end{tabular}




\subsection{Actions Were Taken to Reduce the Barriers to Pursuing STEM}

Amid often compellingly negative incidents our participants described positive actions and supportive and affirming incidents with faculty, advisors, and administrators. Consulting more knowledgeable sources, such as mentors, former or more advanced students as well as professors helped to gain a larger perspective on becoming a scientist. A few telling incidents reflected such reaching out. After giving a presentation at her preliminary exam meeting, Mikayla stepped outside the room while her committee discussed her performance and plans. Sick to her stomach waiting for the second round, the principal investigator of her research happened by and asked how she was feeling after the presentation. He provided reassurance and advised Mikayla to think of the meeting as a scientific conversation and "to just talk to them scientifically".

This advice made me feel so much better and really helped me to pass my prelim examination. Not only did it make me feel more confident about defending my proposal but it also made me feel better knowing that my PI [principal investigator] believed in me.

Mikayla went on to describe how she found that affirming her goals, previously identified as an effective way to counter stereotype threat (Miyake et al. 2010), helped motivate her to persist when facing challenges:

Since my committee meeting I made a point to write down my research goals. Not just what I want to accomplish, but why it is significant. Doing this has helped me to better plan out my experiments (i.e., determining what controls I need) but it has also helped to keep me moving along when an experiment doesn't work out. When something isn't working, instead of focusing on the experiment, I focus on my end goal and try to determine if there is a different or better way to get to it.

Participants sought support from other women for perspective and advice on their mutual experiences. A woman who had already graduated told Teresa, who was thinking about applying for a fellowship, "You should just brag about yourself", encouraging her to promote herself, something women are less comfortable with than men. Some of the participants benefitted from resources available for women in STEM, such as attending WISE (Women in Science and Engineering) programs available at some of the universities. Brooke found a mentor through an online mentoring network.

I got a mentor from MentorNet. ${ }^{3}$ She is wonderful and very useful. I was feeling a bit overwhelmed at the prospect of finding a post-doc and she gave me a set of easily achievable goals that should greatly improve the efficiency of the process. So, I'm going to start writing to potential post-doc advisors and start writing proposals.

Courtney described feeling encouraged after hearing a presentation by women who had succeeded in having families and careers in STEM:

The women's group in my department organized a panel last week on career and family consisting of women in the field who started their families at various stages in their career. Listening to them speak, I was inspired by how practical their decisions were, and how successfully they all seem to have managed to have both a career and a family. I know several of their children and I know they're good mothers. If they can do it, I feel more confident that I can do it soon too.

Some participants had social contacts or family members who provided guidance. For example, Lynn was having advisor problems (her advisor had failed to give her salary for summer work), and

3 http://mentornet.org/organization/programs.html. 
she was discouraged and ready to leave the program. Instead she consulted with her father, a scientist, who helped think the matter through and urged her to stay and learn from the situation, yet, dad's message didn't seem to coach her to do anything about it now.

The women had mixed reactions to their role as models promoting STEM for girls. For example, Anita enjoyed touring a group of girls visiting the lab. "Seeing them skip down the halls and explore our labs and mission ops rooms was thrilling. My hope is that one of those girls was inspired a little to stick with science in high school and maybe college. At the very least, I think they saw that women can be scientists and still "normal" and "girly." In contrast, Tori refused to join in the recruitment of women to the program. "The Profs want you to talk up what a great place this is for women, but I'm not going to lie." She said that potential recruits should know the truth before they commit to a program and laboratory. Yet she did not confront the issue or try to change the practice.

Several women described taking steps to avoid asking questions or sharing their opinions because it risked negative evaluation, or frustration with the response when they did. They avoided speaking up or asking questions for fear that revealing uncertainty would be a viewed sign of weakness. In the "double bind", women evoke negative reactions when they communicate in ways that are counter to female stereotypical prescriptions (Heilman and Okimoto 2007; Rudman and Glick 2001), a phenomenon that is magnified for women of color (Malcom et al. 1976; Ong et al. 2011). Carol reported fearing coming across as too confident and evoking negative stereotypes:

When a woman does act confident and knowledgeable, communicating things in a straightforward, blunt, "male-style" way, reactions are often negative. I've even felt this when communicating with one of my coadvisors. When I act confident, it seems to me that it makes him a little intimidated/uncomfortable. I'm afraid that sometimes in presentations when I answer questions in a straightforward, confident manner that I come off as (sorry for language), some sort of cold, bossy, shrew like, bitch.

Frequently women expressed resignation that their situation was not going to change. As Tori noted:

While the group is not overtly anti-woman, they are not at all interested in changing the balance of things and, why should they? They are working with people they relate to and all the people in power look like them so they don't see anything as being broken. If women or minorities leave, then to them it's just because they weren't smart enough or couldn't work hard enough. But most of the time that's not true.

However, there were also instances of affirmative attempts to request different, more appropriate behaviors, which perhaps point to the personal strengths of the participants. For instance, Linda described confronting her advisor on his negative communication style:

We had a big discussion about that, and he understood and then he apologized for it. He had a way of being pretty brutal verbally, not just with me. It's just a thing about him, and I taught him that he needs to balance out some of his negativity with some encouragement. He knows that this is a problem for him, and he tends to beat up on people at first, but I don't put up with that. So, with me, he usually did not get away with it, so if he said something negative to me that was not well founded, I would address it with him right away.

\subsection{Many Women Expressed Choosing Alternate Career Paths away from Academic Research}

There were several instances in the present study illustrating metaphors used to characterize the decline in numbers and proportions of women at each stage of the career progress in STEM. In fact, the leaky pipelines metaphor may have less value in explaining the choices of women to not pursue academic research careers in STEM (Miller and Wai 2015). Although none of the participants elected to leave their doctoral program during this study, some made decisions that, if carried out, would 
result in movement away from the STEM research career trajectory. The alternatives seemed more attractive and less likely to interfere with pursuing other goals such as romance and having a family. Others were pushed away by conditions in their science environments they judged to be repellent, for example, microaggressions in the masculine culture. We attempted to account for such decisions by the incidents students shared to explain both leaving and persisting in terms of the everyday events and happenings in their personal and professional lives. Specifically, 12 of the 28 women in our study expressed an intention to abandon the traditional trajectory or else made decisions that, de facto, could lead them away from research-intensive careers. The reasons they gave correspond to the incident categories we identified.

\subsubsection{Retreating from the Masculine Culture of STEM}

Leah and Barbara gave reasons associated with the masculine culture for abandoning science research. Although Leah published her research, she had no desire to pursue a research career either in academia or industry; instead, she planned to shift in favor of another career outside of, but informed by her field, where she her contributions would be appreciated, not dismissed. Barbara found the competitive environment of a research-intensive career unappealing and was pulled away by a greater interest in science policy. Sonia might have turned out to be an active scientific researcher but specific incidents of chilly climate convinced her that she did not need "more abusive criticisms" and therefore she rejected her advisor's suggestion that she pursue a post-doctoral position. Ruth felt pushed out of a research career in science, despite having already published, by what she experienced as gratuitous demands of a stressful environment. Although she still wanted to continue doing research, she thought teaching science in community college was a healthier, less stressful alternative to working in a research university or laboratory. Courtney enjoyed her teaching assistantship and community college teaching and felt pulled away from a career in scientific research by a calling to teach. Teresa, already quite accomplished, was discouraged from wanting to pursue an academic career by the competitive pressure to surpass others in the field that she felt from her advisor:

I really don't want to do research. I guess, like I said, everything is just an emergency, but really, it's not an emergency. I might do industrial research, but not in this setting. I don't think I would want to do academic research or be a research professor.

\subsubsection{Prioritizing Relationships, Family and Work-Life Balance}

Five of the women were drawn away from a research career in science by personal relationships and geographic considerations. Danielle wanted to finish her dissertation as soon as possible, so she could marry and move where her boyfriend was stationed. Melanie wanted to find a job wherever her husband found one. Tori felt working near her parents and siblings was more important to her than what kind of job she got. Cheryl wanted to pursue research and obtain a post-doctoral position, and her advisor recommended that she do so. She expressed concern that she might have to limit her search so as not to uproot her family and her husband from his place of employment. Yasmeen, an international student receiving support to come to the U.S. from her home university, had to return to her university and family and resume teaching when she finished her doctorate. Although she would have liked to do research there, the research role was reserved for scholars with seniority that she would not attain for some time, if ever.

\subsubsection{Vignettes Contrasting the Incidents of Two Participants}

The following vignettes summarize incidents reported over a period of six months by two participants, Teresa and Brooke. We include them as a way of contrasting the incidents of one participant who toward the end of the study was moving away from a career in STEM academic research, versus another who remained motivated to become a professor. 
Teresa's experience:

Teresa's first incident was her all male lab mates leaving her out of a social event. Yet she was asked to do tasks like ordering supplies, cleaning up, commonly considered "women's work". She spent a lot of time on non-research or non-independent research that benefitted others rather than her own research. Her advisor frequently pressured her to produce results or finish papers. She felt 'left out of the loop' when important events were planned like inviting a speaker but was then asked to arrange the details of his visit. Recognition was often for her community outreach or helping with another's study rather than for her own research. She had a hard time talking to her advisor about her concerns. Teresa felt spending long hours in the lab left little time for a personal life. She liked being a teaching assistant and considered teaching in a community college. Midway through the study Teresa said, "I don't think I would want to do academic research or be a research professor", where "everything is an emergency." Despite her expertise and several publications, when her advisor talked about her career plans, he asked if she found academic research too stressful; she agreed she did.

\section{Brooke's experience:}

Brooke was excited as the study began because an apparatus she had been building for a month finally worked. She balanced 12-h days in the lab with a "needed" hike the following day. Although she encountered sexual harassment more than once, a professor was supportive and helped her resolve it. Brooke also got positive feedback from faculty and students for her research work. She took advantage of a program matching her with a female mentor in STEM and also had a female alumna as role models she could talk to. Even with the common setbacks, like failing equipment slowing her progress she remained optimistic. "I feel hopeful that I might be able to balance all of this. If I can, perhaps I'm ready for professordom."

The incidents reported by these two women show a cumulative series of events that were similar in some ways but different in others. Both women experienced setbacks common in STEM, struggled with the workload, and wondered how they could balance career and family. However, Teresa lacked female faculty or mentors to advise her and female peers to interact with. Recognition for helping others did not add to her confidence in her own work as a researcher. The pressure to hurry up and produce she felt from her advisor and in the discipline reduced her confidence and interfered with time for balance and personal relationships. In contrast, Brooke felt recognized for her research work and presentations. She also benefitted from the support of female mentors and peers, as well as sympathetic male professors. She maintained balance by hiking and tried to reduce negative thinking. At the end of the study, Teresa, already very accomplished in her specialty, was saying she did not want to pursue a position in an academic research setting. In contrast, Brooke remained expressed motivated to pursue an academic research career despite the challenges. Although we cannot safely speculate that specific incidents in the lives of these individuals directly caused shifts in their career paths, differences in their experiences considered encouraging or discouraging were apparent.

\section{Discussion}

This research examined events during doctoral studies that influenced women's identity as scientists and career aspirations in STEM. We demonstrated a method wherein participants were trained to produce in online reports detailed and current accounts of their actions and interactions with others; and trained interviewers elicited similar detailed accounts. Using these methods, we were able to capture incidents in the women's day-to-day experiences over the course of several months in as close to real time as possible. The results provide a unique glimpse into events that may influence women's persistence in research paths. 
The data from this study suggested several incidents of the women feeling a growing competence that they were making progress and capable of performing the actions of a scientist. Despite the many setbacks, mistakes, and bad times conducting research and submitting manuscripts, their accomplishments suggest that the women in this sample committed sufficient human capital (aptitude, motivation, willingness to work hard and compete) to succeed in research-intensive STEM careers. The women encountered numerous incidents that they reacted to, learned from, and used to formulate a view of themselves making progress toward and away from goals that had initially motivated their doctoral education in STEM. They made headway despite the uncertainties and challenges inevitable in science research. They achieved success in spite of these hurdles and marked their progress as apparatuses were constructed, employed, and repaired, as samples and materials were generated and tested, and as data were modeled, analyzed, and reported. There were markers of their progress, and conference presentations and papers were chief among them. Women were rewarded, recognized, and energized by these rewards and recognitions. In light of the model of identity proposed by Carlone and Johnson (2007), the participants demonstrated remarkable competence and performed at high levels. Most recognized themselves as developing scientists and were recognized by significant others as emerging scientists. At this critical time in their career development, many of the women in our study were succeeding in entering their fields as capable contributors with plans to continue.

At the same time, incidents revealed impediments that were not so easily surmounted. Nearly all of the participants encountered historical and cultural structures, such as the overwhelming disparity of males to females in the workplace, and the low number of female advisors or mentors that discouraged and, in a few cases, actually pushed them away from their identities as scientists and even from their original career intentions. Despite societal attempts to level opportunities and treatment of women, the masculinized STEM culture provided many reminders that women were less valuable, less capable, and unwelcome compared to men. Few incidents pointed to outright discrimination and harassment but there were frequent accounts of microaggressions that, in a few cases, pushed women out. Similar to findings by Robnett (2015), sexism was sometimes explicit, but usually implicit in ways that over time decreased STEM self-concept and expectations of being able to succeed in STEM. An incident did not have to happen to a woman currently in order for it to have an effect, but could be an event that occurred in the past or that occurred to someone else within her community (Raver and Gelfand 2005; Settles et al. 2013). Thus, knowing female peers who had been discriminated against or harassed had effects that were contemporary and personal. The data depict how the climate becomes chilly, i.e., who communicates through direct and indirect microaggressions that women are unwelcome and do not belong (Hall and Sandler 1982; Lewis et al. 2017; Sue 2010).

There was less evidence to indicate that work-life balance directly hindered the women's growing identification as scientists, perhaps because few were married or had children, but it did lead some women to question their career paths. Several of the participants mentioned concern that they had put off that phase of their lives to prioritize their science careers. Learning about women who were able to successfully navigate family and career dispelled some of this apprehension and shifted thinking toward a more optimistic view of work-life balance (Tan-Wilson and Stamp 2015). However, some women began to consider the cost-benefit ratio involved in weak job markets for academic careers, the requirements for spending several years in post-doctoral work and intense pressure to set up laboratories and publish in competitive journals, weighed against what one participant called, "a normal life." Such consideration usually came as a result of specific events in the cultural and interactional environment, such as seeing their non-science contemporaries marry and have families, and not the result of personal failures, unwillingness to put forth sufficient effort, or incompetence.

Some women at difficult times reached out to a variety of human sources-people who provided a broader prospective on the graduate student experience. Young et al. (2013) found that having positive female role models such as professors or mentors reduced the impact of gendered stereotypes and improved career aspirations. In fact, a number of the women in our study indicated they sought out other female students and mentors, as well as participating in programs through their universities 
to raise awareness and provide support to women in STEM fields. Still, almost all women in the study believed there were not enough women faculty or peers in their program.

This study extends the literature on women in science and engineering in several ways. Because our focus was on incidents, we reported incidents in the women's own words that were salient for them, at the time they occurred, and accumulated to inform individual choices for future career directions. A unique feature was our longitudinal approach in following, in real time, the incidents reported by women over seven months of their advanced doctoral studies. In contrast to many studies that focus on the trying challenges that women face in the sciences and engineering, we identified both encouraging and discouraging incidents in the daily lives of participants that are often overlooked. The research provides real examples that can be utilized by counselors and mentors to inform other women students facing similar situations. The findings reinforce the need for structural and institutional changes that increase the availability of advisors, mentors and programs that expand opportunities for women, help validate women's experiences, provide resources for and model feasible ways to combine science careers with personal life, and support women in managing difficulties. Many of the incidents recounted by women reflected the communication by others of implicit bias and tacit acceptance of norms in male-dominated disciplines. These findings add weight to the need for educating faculty, students, and others in the university setting to recognize what incidents women experience as motivating or discouraging. With a better understanding of the daily experiences that contribute to persistence and the development of career intentions within STEM, the study points to a direction for improving environments that support doctoral-level women in science and engineering.

\section{Limitations}

It was important for the researchers and participants to be able to recognize what might constitute an incident, and the process of directing attention may have raised awareness validating the women's experiences in a way that supported their views. The frequency of the data points over time, biweekly for interviews and weekly for online posts, still permitted details of some of the incidents to be forgotten as others took precedence. Nonetheless what we may have missed in not observing the incidents directly we captured by gathering data over a longer period of time, through the words of the participants.

Our focus on incidents was without trying to associate them with specific characteristics of the women who experienced them. To do otherwise would have required far more participants, or revealing more personal information and possibly the identity of the participants. We also did not describe characteristics of university programs that were supportive or discouraging of women in STEM, although this is likely an important factor in student persistence (Ferreira 2003b). Instead, our study looked at incidents in the women's formulation of themselves as scientists and their aspirations. Other research has found that in STEM departments with academic cultures that emphasize diversity and inclusion, women's attitudes improve about their potential to succeed (Frieze et al. 2011).

The recruitment strategy that we used increased the probability of attracting volunteers who were willing to devote the considerable time involved to complete, over an extended period, a series of interviews and blogs. This was likely to have reduced the number of women volunteers with families or with primary languages other than English. Limiting recruitment to departments with 15 or more women in a doctoral program precluded including participants from the many smaller departments and from those where women are even more underrepresented. These environments for women are likely to be different and constitute an area for future study. Our numbers did not allow us to consider the unique experiences of racial and ethnic minority women in STEM graduate programs, an area critically important to explore for deeper understanding of how multiple marginalities affect experience and science career intentions (McGee et al. 2016; Ong et al. 2011). Additionally, our sample and promise of confidentiality prevented us from examining the experiences of international students or exploring disciplinary factors. As well, the study focused only on women. Future studies should 
extend to doctoral students the investigation of how men and women experience their journey through graduate programs and paths to STEM and non-STEM careers.

\section{Conclusions}

The attrition of women from doctoral programs in STEM before earning the degree, is not only a personal loss to the individuals involved and to science innovation informed by diverse contributors, but reduces the chance of addressing some of the problems associated with the STEM culture such as a dearth of women faculty. However, the metaphor of the leaky pipeline, considered solely as attrition from graduate study in STEM, was of limited value in following the trajectory of the advanced students in the study. During the period of our data collection, all participants intended to finish their degrees.

Rather, our data indicated a shift in intended pathways for some women during the later stages of their degree programs. Over one-third of the participants in our study indicated that although they were likely to earn the $\mathrm{PhD}$, they would seek alternative paths and different careers within STEM that were not research-intensive. Our results from following women's experiences over seven months deepen our understanding of the real-time conditions under which career intentions develop and change for women. Our participants were in their third or fourth year, past the time when many doctoral students question their ability or interest in the field. The students were in the physical sciences or engineering, in departments where women faculty numbered none or one for several of the participants. In these contexts, many incidents demonstrated women responding to alienating or discouraging events by trying to improve the culture for themselves and their peers. Some made choices and decisions that had the potential to move them off the traditional pathway and away from research-intensive careers and the professoriate for a variety of reasons. In some cases, the women sought opportunities they felt permitted multiple goals, such as family and career (Barthelemy et al. 2015; Roach and Sauermann 2017). Alternative career interests-teaching, law, and policy_pulled away a few women and suggested a move toward what Carlone and Johnson (2007) referred to as altruistic careers. Still others were likely pushed away by unfriendly environments, as many incidents revealed the enduring presence of an alienating culture and microaggressions. Nevertheless, the bulk of happenings in the lives of graduate women in STEM revealed their growing identification as scientists in the making.

Acknowledgments: The authors express appreciation to Mary Lee Smith for her contributions to the conception, design, data collection, and early drafts of the paper. We also thank Caroline Harrison and Erin Kube for their help at the start of the research and Jessica Borders and Bethany Smith for their help on the manuscript. In addition, the authors would like to extend appreciation to all of the women who shared their experiences while participating in the study.

Author Contributions: Marilyn Cabay collected and analyzed data and was instrumental in writing the paper; Bianca Bernstein led the funding acquisition for the CareerWISE research program of which this study was part, and collaborated in designing the research and writing the paper; Melissa Rivers collected and analyzed data and contributed to early drafts of the paper; Natalie Fabert collected and analyzed data.

Conflicts of Interest: The authors declare no conflict of interest. This study was supported by the National Science Foundation (NSF) under grants 0634519 and 0910384 . The funding sponsors had no role in the design of the study; in the collection, analyses, or interpretation of data; in the writing of the manuscript, and in the decision to publish the results.

\section{References}

American Physical Society. 2015. 15.2 Statement on the Status of Women in Physics. Available online: http: / / www.aps.org/policy/statements/15_2.cfm (accessed on 17 April 2016).

Barthelemy, Ramon, Melinda McCormick, and Charles Henderson. 2015. Barriers beyond equity: An exploratory study of women graduate students' career pathways in astronomy. International Journal of Gender, Science and Technology 7: 57-73.

Basford, Tessa E., Lynn R. Offermann, and Tara S. Behrend. 2014. Do you see what I see? Perceptions of gender microaggressions in the workplace. Psychology of Women Quarterly 38: 340-49. [CrossRef] 
Beasley, Maya A., and Mary J. Fischer. 2012. Why they leave: The impact of stereotype threat on the attrition of women and minorities from science, math and engineering majors. Social Psychology of Education 15: 427-48. [CrossRef]

Bekki, Jennifer M., Mary Lee Smith, Bianca L. Bernstein, and Caroline J. Harrison. 2013. Effects of an Online Personal Resilience Training Program for Women in STEM Doctoral Programs. Journal of Women and Minorities in Science and Engineering 19: 17-35. [CrossRef]

Bekki, Jennifer M., Bianca L. Bernstein, Natalie S. Fabert, Natalie J. Gildar, and Amy Way. 2014. Efficacy of an online resource for teaching interpersonal problem solving skills to women graduate students in engineering. Advances in Engineering Education 4: 1-27.

Bernstein, Bianca L. 2011. Managing barriers and building supports in science and engineering doctoral programs: Underpinnings for a new online training program for women. Journal of Women and Minorities in Science and Engineering 17: 29-50. [CrossRef]

Bernstein, Bianca, and Nancy Felipe Russo. 2008. Explaining too few women in academic science and engineering careers: A psychosocial perspective. In The Psychology of Women at Work: Challenges and Solutions for Our Female Workforce. Edited by Michele A. Paludi. Wesport: Praeger Press, vol. 2, pp. 1-33.

Bernstein, Bianca L., and Nancy Felipe Russo. 2007. Career paths and family in the academy: Progress and challenges. In Work, Life, and Family Imbalance: How to Level the Playing Field. Edited by Michele Antoinette Paludi and Presha E. Neidermeyer. Westport: Praeger Press, pp. 89-119.

Beyer, Sylvia. 2014. Why are women underrepresented in computer science? Gender differences in stereotypes, self-efficacy, values, and interests and predictors of future CS course-taking and grades. Computer Science Education 24: 153-92. [CrossRef]

Blickenstaff, Jacob C. 2005. Women and science careers: Leaky pipeline or gender filter? Gender and Education 17: 369-86. [CrossRef]

Blumer, Herbert. 1969. Symbolic Interactionism. Englewood Cliffs: Prentice Hall.

Bolger, Niall, Angelina Davis, and Eshkol Rafaeli. 2003. Diary methods: Capturing life as it is lived. Annual Review of Psychology 54: 579-616. [CrossRef]

Britton, Dana M., Chardie L. Baird, Ruth A. Dyer, B. Jan Middendorf, Beth A. Montelone, and Christa Smith. 2012. Surveying the campus climate for faculty: A comparison of the assessments of STEM and non-STEM faculty. International Journal of Gender, Science and Technology 4: 103-22.

Cadsby, C. Bram, Maroš Servátka, and Fei Song. 2013. How competitive are female professionals? A tale of identity conflict. Journal of Economic Behavior E Organization 92: 284-303. [CrossRef]

Carlone, H. B., and Angela Johnson. 2007. Understanding the science experiences of successful women of color: Science identity as an analytic lens. Journal of Research in Science Teaching 44: 1187-218. [CrossRef]

Ceci, Stephen J., Wendy M. Williams, and Susan M. Barnett. 2009. Women's underrepresentation in science: Sociocultural and biological considerations. Psychological Bulletin 135: 218-61. [CrossRef] [PubMed]

Clancy, K. B. H., Robin G. Nelson, Julienne. N. Rutherford, and Katie Hinde. 2014. Survey of Academic Field Experiences (SAFE): Trainees Report Harassment and Assault. PLoS ONE 9: e102172. [CrossRef] [PubMed]

Clancy, Kathryn B. H., Katherine M. N. Lee, Erica M. Rodgers, and Christina Richey. 2017. Double jeopardy in astronomy and planetary science: Women of color face greater risks of gendered and racial harassment. Journal of Geophysical Research: Planets 122: 1610-23. [CrossRef]

Committee on Maximizing the Potential of Women in Academic Science and Engineering. 2007. Beyond Bias and Barriers: Fulfilling and Potential of Women in Academic Science and Engineering. National Academy of Sciences, National Academy of Engineering, and Institute of Medicine of the National Academies; Washington, DC: National Academies Press.

Concannon, James P., and Lloyd H. Barrow. 2010. Men's and women's intentions to persist in undergraduate engineering degree programs. Journal of Science Education and Technology 19: 133-45. [CrossRef]

Danielsson, Anna Teresia. 2012. Exploring woman University physics students doing gender and doing physics. Gender and Education 24: 25-39. [CrossRef]

Danielsson, Anna Teresia, and Cedric Linder. 2009. Learning in physics by doing laboratory work: Towards a new conceptual framework. Gender and Education 21: 129-44. [CrossRef]

De Welde, Kris, and Sandra L. Laursen. 2011. The glass obstacle course: Informal and formal barriers for women Ph.D. students in STEM fields. International Journal of Gender, Science, and Technology 3: 571-95. 
Du, Xiang-Yun. 2006. Gendered practices of constructing an engineering identity in a problem-based learning environment. European Journal of Engineering Education 31: 35-42. [CrossRef]

Erickson, Frederick. 1986. Qualitative methods in research on teaching. In Handbook of Research on Teaching. Edited by Merlin Wittrock. New York: Macmillan.

Etzkowitz, Henry, Carol Kemelgor, and Brian Uzzi. 2000. Athena Unbound: The Advancement of Women in Science and Technology. Cambridge: Cambridge University Press.

Fabert, Natalie, and Bianca Bernstein. 2009. Women's Attrition from STEM Doctoral Programs: Reflections from Non-Completers. Toronto: American Psychological Association.

Fabert, Natalie, Mary L. Smith, Marilyn Cabay, Melissa B. Rivers, and Bernstein L. Bernstein. 2011. Exaggerating the typical, stereotyping the differences: Isolation experienced by women in STEM doctoral programs. Paper present at the American Society for Engineering Education Annual Conference and Exhibition, Vancouver, BC, Canada, June 26-29.

Faulkner, W. 2007. 'Nuts and bolts and people': Gender-troubled engineering. Social Studies of Science 37: 331-56. [CrossRef]

Ferreira, Maria M. 2003a. Gender differences in graduate students' perspectives on the culture of science. Journal of Women and Minorities in Science and Engineering 9: 119-35. [CrossRef]

Ferreira, Maria M. 2003b. Gender issues related to graduate student attrition in two science departments. International Journal of Science Education 25: 969-89. [CrossRef]

Fouad, Nadya A., Romila Singh, Kevin Cappaert, Wen-hsin Chang, and Min Wan. 2016. Comparison of women engineers who persist in or depart from engineering. Journal of Vocational Behavior 92: 79-93. [CrossRef]

Fox, Mary Frank. 2001. Women, science, and academia: Graduate education and careers. Gender $\mathcal{E}$ Society 15: 664-66. [CrossRef]

Fox, Mary Frank. 2010. Women and men faculty in academic science and engineering: Social-organizational indicators and implications. American Behavioral Scientist 53: 997-1012. [CrossRef]

Fox, Mary Frank, Gerhard Sonnert, and Irina Nikiforova. 2011. Programs for undergraduate women in science and engineering: Issues, problems, and solutions. Gender \& Society 25: 589-615. [CrossRef]

Franzway, Suzanne, Rhonda Sharp, Julie E. Mills, and Judith Gill. 2009. Engineering ignorance: The problem of gender equity in engineering. Frontiers: A Journal of Women Studies 30: 89-106. [CrossRef]

Frieze, Carol, Jeria L. Quesenberry, Elizabeth Kemp, and Anthony Velazquez. 2011. Diversity or difference? New research supports the case for a cultural perspective on women in computing. Journal of Science Education and Technology 21: 423-39. [CrossRef]

Fuhrman, Cynthia N., Dina G. Halme, Patricia S. O'Sullivan, and Bill Lindstaedt. 2011. Improving graduate education to support a branching career pipieline: Recommendations based on a survey of doctoral students in the basic biomedical sciences. CBE Life Sciences Education 10: 239-49. [CrossRef] [PubMed]

Gee, James Paul. 1999. An Introduction to Discourse Analysis: Theory and Method. New York: Routledge.

Gibbs, Kenneth D., Jr., and Kimberly A. Griffin. 2013. What do I want to be with my PhD? The roles of personal values and structural dynamics in shaping the career interests of recent biomedical science PhD graduates. CBE Life Sciences Education 12: 711-23. [CrossRef] [PubMed]

Glass, Jennifer L., Sharon Sassler, Yael Levitte, and Katherine M. Michelmore. 2013. What's So Special about STEM? A comparison of women's retention in STEM and professional occupations. Social Forces 92: 723-56. [CrossRef] [PubMed]

Glick, Peter, and Susan T. Fiske. 1996. The Ambivalent Sexism Inventory: Differentiating hostile and benevolent sexism. Journal of Personality and Social Psychology 70: 491-512. [CrossRef]

Gokhale, Anu, Cara Rabe-Hemp, Lori Woeste, and Kenton Machina. 2014. Gender differences in attitudes towards science and technology among majors. Journal of Science Education and Technology 24: 509-16. [CrossRef]

Golde, Chris M. 2005. Should I stay or should I go? Student descriptions of the doctoral attrition process. Review of Higher Education 23: 119-227. [CrossRef]

Gonsalves, Allison J. 2014. "Physics and the girly girl-There is a contradiction somewhere": Doctoral students" positioning around discourses of gender and competence in physics. Cultural Studies of Science Education 9: 503-21. [CrossRef]

Good, Catherine, Aneeta Rattan, and Carol S. Dweck. 2012. Why do women opt out? Sense of belonging and women's representation in mathematics. Journal of Personality and Social Psychology 102: 700-17. [CrossRef] [PubMed] 
Goulden, Marc, Karie Frasch, and Mary Ann Mason. 2009. Staying Competitive: Patching America's Leaky Pipeline in the Sciences. Berkeley: Berkeley Center on Health, Economic, \& Family Security and the Center for American Progress.

Griffith, Amanda L. 2010. Persistence of women and minorities in STEM field majors: Is it the school that matters? Economics of Education Review 29: 911-22. [CrossRef]

Grunert, Megan, and George M. Bobnerb. 2011. Finding fulfillment: Women's self-efficacy beliefs and career choices in chemistry. Chemical Education Research and Practice 12: 420-26. [CrossRef]

Gunter, Ramona, and Amy Stambach. 2005. Differences in men and women scientists' perceptions of workplace climate. Journal of Women and Minorities in Science and Engineering 11: 97-116. [CrossRef]

Hall, Roberta M., and Bernice R. Sandler. 1982. The Campus Climate: A Chilly One for Women? Project on the Status and Education of Women. Washington, DC: Association of American Colleges.

Handelsman, Jo, Nancy Cantor, Molly Carnes, Denice Denton, Eve Fine, Barbara Grosz, Virginia Hinshaw, Cora Marrett, Sue Rosser, Donna Shalala, and et al. 2005. More women in science. Science 309: 1190-91. [CrossRef] [PubMed]

Hartman, Harriet, and Moshe Hartman. 2008. How undergraduate engineering students perceive Women's (and Men's) problems in science, math and engineering. Sex Roles 58: 251-65. [CrossRef]

Heilman, Madeline E., and Tyler G. Okimoto. 2007. Why are women penalized for success at male tasks? The implied communality deficit. Journal of Applied Psychology 92: 81-92. [CrossRef] [PubMed]

Herzig, Abbe H. 2004a. 'Slaughtering this beautiful math': Graduate women choosing and leaving mathematics. Gender and Education 16: 379-95. [CrossRef]

Herzig, Abbe H. 2004b. Becoming mathematicians: Women and students of color choosing and leaving doctoral mathematics. Review of Educational Research 74: 171-214. [CrossRef]

Hill, Catherine, Christianne Corbett, Andrese St R., and the American Association of University Women. 2010. Why So Few?: Women in Science, Technology, Engineering, and Mathematics. Washington: AAUW.

HyperRESEARCH 2.8.3. 2009. Computer Software. Randolph: Researchware, Inc. Available online: http:/ / www. researchware.com/ (accessed on 18 May 2009).

Ivie, Rachel, and Cassie L. Tesfaye. 2012. Women in physics: A tale of limits. Physics Today 65: 47-50. [CrossRef]

Kaminski, Deborah, and Cheryl Geisler. 2011. Survival analysis of faculty retention in science and engineering by gender. Science 335: 864-66. [CrossRef] [PubMed]

Kanter, Rosabeth M. 1977. Some Effects of Proportions on Group Life: Skewed Sex Ratios and Responses to Token Women. American Journal of Sociology 82: 965-990. [CrossRef]

Kiefer, Amy K., and Denise Sekaquaptewa. 2007. Implicit stereotypes and women's math performance: How implicit gender-math stereotypes influence women's susceptibility to stereotype threat. Journal of Experimental Social Psychology 43: 825-32. [CrossRef]

Margaret F. King, ed. 2008. Ph.D. Completion and Attrition: Analysis of Baseline Demographic Data from the Ph.D.. Completion Project; Washington: Council of Graduate Schools.

Kmec, Julie A. 2013. Why academic STEM mothers feel they have to work harder than others on the job. International Journal of Gender, Science and Technology 5: 79-101.

Levine, Rachel B., Fenny Lin, David E. Kern, Scott M. Wright, and Joseph Carrese. 2011. Stories from early-career women physicians who have left academic medicine: A qualitative study at a single institution. Academic Medicine 86: 752-58. [CrossRef] [PubMed]

Lewis, Karyn L., Jane G. Stout, Noah D. Finkelstein, Steven J. Pollock, Akira Miyake, Geoff L. Cohen, and Tiffany A. Ito. 2017. Fitting in to move forward: Belonging, gender, and persistence in the physical sciences, technology, engineering, and mathematics (pSTEM). Psychology of Women Quarterly 41: 420-36. [CrossRef]

Logel, Christine, George M. Walton, Steven J. Spencer, Emma C. Iserman, William von Hippel, and Amy Bell. 2009. Interacting with sexist men triggers social identity threat among female engineers. Journal of Personality and Social Psychology 96: 1089-103. [CrossRef] [PubMed]

London, Bonita, Lisa Rosenthal, Sheri R. Levy, and Marci Lobel. 2011. The influences of perceived identity compatibility and social support on women in nontraditional fields during the college transition. Basic and Applied Social Psychology 33: 304-21. [CrossRef]

Lott, Joe L., Susan Gardner, and Daniel A. Powers. 2009. Doctoral student attrition in the STEM fields: An exploratory event history analysis. Journal of College Student Retention: Research, Theory and Practice 11: 247-66. [CrossRef] 
Lovitts, Barbara. 2001. Leaving the Ivory Tower: The Causes and Consequences of Departure from Doctoral Study. Lanham: Rowman and Littlefield.

Malcom, Shirley, Paula Hall, and Janel W. Brown. 1976. The Double Bind: The Price of Being a Minority Woman in Science. Washington: American Association for the Advancement of Science.

Mason, Mary A., and Eve M. Ekman. 2007. Mothers on the Fast Track. New York: Oxford University Press.

Mason, Mary A., Marc Goulden, and Karie Frasch. 2009. Why graduate students reject the fast track. Academe 95: 11-16.

Mason, Mary A., Nicholas H. Wolfinger, and Marc Goulden. 2013. Do Babies Matter? Gender and Family in the Ivory Tower. New Brunswick: Rutgers University Press.

Maxwell, Joseph A. 2005. Qualitative Research Design: An Interactive Approach, 2nd ed. Thousand Oaks: Sage.

McGee, Ebony O., Devin T. White, Akaila T. Jenkins, Stacey Houston, Lydia C. Bentley, William J. Smith, and William H. Robinson. 2016. Black engineering students' motivation for PhD attainment: Passion plus purpose. Journal for Multicultural Education 10: 167-93. [CrossRef]

Merolla, David M., and Richard T. Serpe. 2013. STEM enrichment programs and graduate school matriculation: The role of science identity salience. Social Psychology of Education: An International Journal 16: 575-97. [CrossRef] [PubMed]

Miller, David I., and Jonathan Wai. 2015. The bachelor's to Ph.D. STEM pipeline no longer leaks more women than men: A 30-year analysis. Frontiers of Psychology 6. [CrossRef]

Miller, David I., Alice H. Eagly, and Marcia C. Linn. 2015. Women's representation in science predicts national gender-science stereotypes: Evidence from 66 nations. Journal of Educational Psychology 107: 631-44. [CrossRef]

Mincer, Jacob, and Solomon Polachek. 1974. Family investments in human capital: Earnings of women. Journal of Political Economy 82: 76-110. [CrossRef]

Massachusetts Institute of Technology (MIT). 1999. Report on the Status of Women Faculty at MIT. Cambridge: MIT, Available online: http: / facultygovernance.mit.edu/sites / default / files / reports /2002-03_Status_of_ Women_Faculty-All_Reports.pdf (accessed on 12 December 2017).

Miyake, Akira, Lauren E. Kost-Smith, Noah D. Finkelstein, Steven J. Pollock, Geoffrey L. Cohen, and Tiffany A. Ito. 2010. Reducing the gender achievement gap in college science: A classroom study of values affirmation. Science 330: 1234-37. [CrossRef] [PubMed]

Moody, Janette W., J. Ellis Blanton, and Paul H. Cheney. 1998. A theoretically grounded approach to assist memory recall during information requirements determination. Journal of Management Information Systems 15: 79-98. [CrossRef]

Moors, Amy C., Janet E. Malley, and Abigail J. Stewart. 2014. My family matters: Gender and perceived support for family commitments and satisfaction in academia among postdocs and faculty in STEMM and non-STEMM fields. Psychology of Women Quarterly 38: 460-74. [CrossRef]

Moss-Racusin, Corinne A., and Laurie A. Rudman. 2010. Disruptions in women's self-promotions: The AVOIDANCE MODEL: The backlash avoidance model. Psychology of Women Quarterly 34: 186-202. [CrossRef]

Moss-Racusin, Corinne A., John F. Dovidio, Victoria L. Brescoll, Mark J. Graham, and Jo Handelsman. 2012. Science faculty's subtle gender biases favor male students. Proceedings of the National Academy of Sciences United States of America 109: 16474-479. [CrossRef] [PubMed]

Nadelson, Louis S., Sharon P. McGuire, Kristen A. Davis, Arvin Farid, Kimberly K. Hardy, Yu-Chang Hsu, Uwe Kaiser, Rajesh Nagarajan, and Sasha Wang. 2015. Am I a STEM professional? Documenting STEM student professional identity development. Studies in Higher Education, 1-20. [CrossRef]

Committee on Status and Participation of Women in STEM Disciplines and Careers, Committee on Women in Science, Engineering, and Medicine, and Policy and Global Affairs. 2012. Blueprint for the Future: Framing the Issues of Women in Science in a Global Context, Summary of a Workshop. Edited by Catherine Didion, Lisa M. Frehill and Willie Pearson. Washington: The National Academies Press.

National Science Foundation. 2016. National Center for Science and Engineering Statistics (2017). Doctorate Recipients from U.S. Universities: 2016. NSF 18-304. Available online: https:/ /www.nsf.gov/statistics/ 2018/nsf18304/data.cfm (accessed on 6 January 2018). 
National Science Foundation. 2017. Women, Minorities, and Persons with Disabilities in Science and Engineering: 2017. In National Center for Science and Engineering Statistics (2017); Special Report NSF 17-310; Arlington: NCSES Publications. Available online: www.nsf.gov/statistics/wmpd/ (accessed on 6 January 2018).

Nettles, Michael T., and Catherine M. Millett. 2006. Three Magic Letters: Getting to Ph.D.. Baltimore: The Johns Hopkins University Press.

Ong, Maria, Carol Wright, Lorelle L. Espinosa, and Gary Orfield. 2011. Inside the double bind: A synthesis of empirical research on undergraduate and graduate women of color in science, technology, engineering, and mathematics. Harvard Educational Review 81: 172-209. [CrossRef]

Polachek, Solomon. 2004. How the human capital model explains why the gender wage gap narrowed. In The Declining Significance of Gender? Edited by Francine D. Blau, Mary C. Brinton and David B. Grusky. New York: Russell Sage Foundation.

Raver, Jana L., and Michele J. Gelfand. 2005. Beyond the individual victim: Linking sexual harassment, team processes, and team performance. Academy of Management Journal 48: 387-400. [CrossRef]

Reuben, Ernesto, Paola Sapienza, and Luigi Zingales. 2014. How stereotypes impair women's careers in science. PNAS 111: 4403-8. [CrossRef] [PubMed]

Rhoton, Laura A. 2011. Distancing as a gendered barrier: Understanding women scientists' gender practices. Gender and Society 25: 696-716. [CrossRef]

Roach, Michael, and Henry Sauermann. 2017. The declining interest in an academic career. PLoS ONE 12: e0184130. [CrossRef] [PubMed]

Robnett, Rachel D. 2015. Gender bias in STEM fields: Variation in prevalence and links to STEM self-concept. Psychology of Women Quarterly 40: 65-79. [CrossRef]

Rossi, Alice S. 1965. Women in science: Why so few? Social and psychological influences restrict women's choice and pursuit of careers in science. Science 148: 1196-202. [CrossRef] [PubMed]

Rudman, Laura A., and Peter Glick. 2001. Prescriptive gender stereotypes and backlash toward agentic women. Journal of Social Issues 57: 743-62. [CrossRef]

Saldana, Johnny. 2003. Longitudinal Qualitative Research: Analyzing Change through Time. Lanham: AltaMira Press.

Sauermann, Henry, and Michael Roach. 2012. Science PhD Career Preferences: Levels, Changes, and Advisor Encouragement. PLoS ONE 7: e36307. [CrossRef] [PubMed]

Schumann, Karina, and Michael Ross. 2010. Why women apologize more than men: Gender differences in thresholds for perceiving offensive behavior. Psychological Science 21: 1649-55. [CrossRef] [PubMed]

Settles, Isis H., Lilia M. Cortina, NiCole T. Buchanan, and Kathi N. Miner. 2013. Derogation, discrimination, and (dis)satisfaction with jobs in science: A gendered analysis. Psychology of Women Quarterly 37: 179-91. [CrossRef]

Shauman, Kimberlee A. 2017. Gender differences in the early employment outcomes of STEM doctorates. Social Sciences 6. [CrossRef]

Smyth, Frederick L., and Brian A. Nosek. 2015. On the gender-science stereotypes held by scientists: Explicit accord with gender-ratios, implicit accord with scientific identity. Frontiers in Psychology 6: 415. [CrossRef] [PubMed]

Sonnert, Gerhard, and Gerald Holton. 1995. Who Succeeds in Science: The Gender Dimension. New Brunswick: Rutgers University Press.

Sowell, Richard, Jeff Allum, and Hiranoa Okahana. 2015. Doctoral Initiative on Minority Attrition and Completion. Washington: Council of Graduate Schools.

Spelke, Elizabeth S. 2005. Sex differences in intrinsic aptitude for mathematics and science? A critical review. American Psychologist 60: 950-58. [CrossRef]

Spradley, James P. 1979. The Ethnographic Interview. New York: Holt, Rinehart \& Winston.

Sue, Derald W. 2010. Microaggressions in Everyday Life: Race, Gender, and Sexual Orientation. Hoboken: Wiley.

Sue, Derald W., Christina M. Capodilupo, Gina C. Torino, Jennifer M. Bucceri, Aisha Holder, Kevin L. Nadal, and Maria Esquilin. 2007. Racial microaggressions in everyday life: Implications for clinical practice. American Psychologist 62: 271. [CrossRef] [PubMed]

Tan-Wilson, Anna, and Nancy Stamp. 2015. College students' views of work-life balance in STEM research careers: Addressing negative preconceptions. CBE-Life Sciences Education 14: 1-13. [CrossRef] [PubMed]

Tate, Erika D., and Marcia C. Linn. 2005. How does identity shape the experiences of women of color engineering students? Journal of Science Education and Technology 14: 483-93. [CrossRef] 
Thoman, Dustin B., Jessica A. Arizaga, Jesse L. Smit, Tyler S. Story, and Gretchen Soncuya. 2014. The grass is greener in non-science, technology, engineering, and math classes: Examining the role of competing belonging to undergraduate women's vulnerability to being pulled away from science. Psychology of Women Quarterly 38: 246-58. [CrossRef]

Tonso, Karen L. 2006. Student engineers and engineer identity: Campus engineer identities as figured world. Cultural Studies of Science Education 1: 237-307. [CrossRef]

Travers, Cheryl. 2011. Unveiling a reflective diary methodology for exploring the lived experiences of stress and coping. Journal of Vocational Behavior 79: 204-16. [CrossRef]

Turk-Bicakci, Lori, and Andrea Berger. 2014. Leaving STEM: STEM Ph.D. Holders in non-STEM Careers. Issue Brief. American Institutes for Research. Available online: http: / www.air.org/resource/leaving-stem-stemph-d-holders-non-stem-careers (accessed on 12 December 2017).

Ülkü-Steiner, Beril, Beth Kurtz-Costes, and C. Ryan Kinlaw. 2000. Doctoral student experiences in gender-balanced and male-dominated graduate programs. Journal of Educational Psychology 92: 296-307. [CrossRef]

Walton, Gregory M., Mary C. Murphy, and Ann M. Ryan. 2015. Stereotype threat in organizations: Implications for equity and performance. Annual Review of Organizational Psychology and Organizational Behavior 2: 523-50. [CrossRef]

White, Susan, and Rachel Ivie. 2013. Report: Number of Women in Physics Departments: A simulation Analysis (1-13). American Institute of Physics Report; College Park: American Institute of Physics, Available online: https: / www.aip.org/sites/default/files/statistics/faculty / womenindepts-p-10.pdf (accessed on 12 December 2017).

White House Office of Science and Technology Policy. 2016. Women in STEM. Available online: https://www. whitehouse.gov/administration/eop/ostp/women (accessed on 16 November 2017).

Wolfe, Joanna. 2012. Communication styles in engineering and other male-dominated fields. Applying Research to Practice (ARP) Resources. Edited by B. Bogue and E. Cady. Available online: http:/ / www.engr.psu.edu/awe/ ARPresources.aspx (accessed on 20 November 2017).

Wolfe, Jennifer, and Elizabeth Powell. 2009. Biases in interpersonal communication: How engineering students perceive gender typical speech acts in teamwork. Journal of Engineering Education 98: 5-16. [CrossRef]

Wyer, Mary. 2003. Intending to stay: Images of scientists, attitudes toward women, and gender as influences on persistence among science and engineering majors. Journal of Women and Minorities in Science and Engineering 9: 1-16. [CrossRef]

Xie, Yu, and Kimberlee A. Shauman. 2003. Women in Science: Career Processes and Outcomes. Cambridge: Harvard University Press.

Xu, Yonghong J. 2008. Gender disparity in STEM disciplines: A study of faculty attrition and turnover intentions. Research in Higher Education 49: 607-24. [CrossRef]

Young, Danielle M., Laurie A. Rudman, Helen M. Buettner, and Mehgan C. McLean. 2013. The influence of female role models on women's implicit science cognitions. Psychology of Women Quarterly 37: 283-92. [CrossRef]

Zeldin, Amy L., and Frank Pajares. 2000. Against the odds: Self-efficacy beliefs of women in mathematical, scientific, and technological careers. American Educational Research Journal 37: 215-46. Available online: http:/ / www.jstor.org/stable/1163477 (accessed on 16 June 2015). [CrossRef]

Zeldin, Amy L., Shari L. Britner, and Frank Pajares. 2008. A comparative study of the self-efficacy beliefs of successful men and women in mathematics, science, and technology careers. Journal of Research in Science Teaching 45: 1036-58. [CrossRef]

(C) 2018 by the authors. Licensee MDPI, Basel, Switzerland. This article is an open access article distributed under the terms and conditions of the Creative Commons Attribution (CC BY) license (http://creativecommons.org/licenses/by/4.0/). 